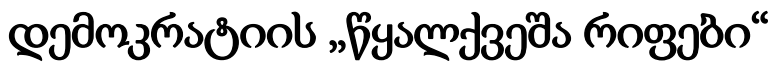

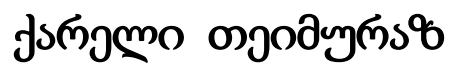

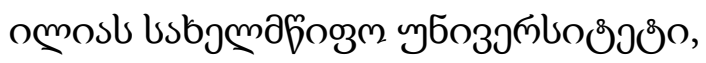

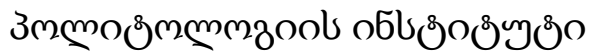

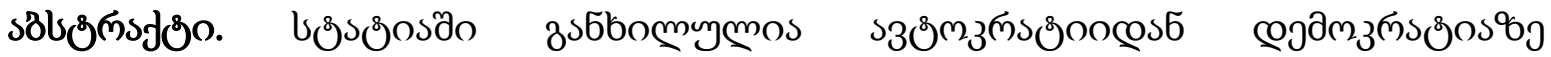

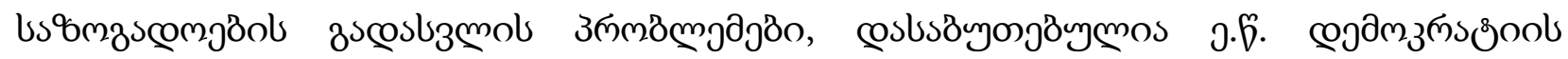

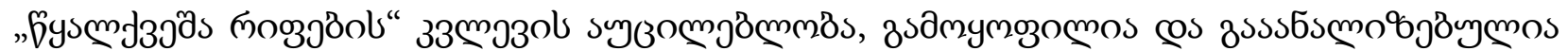

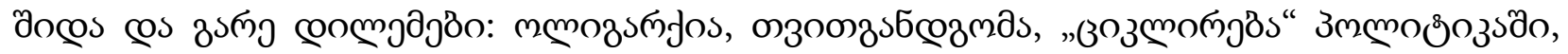

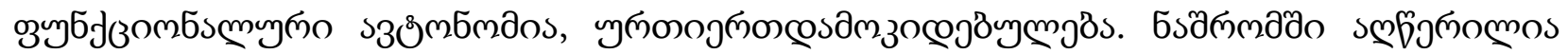

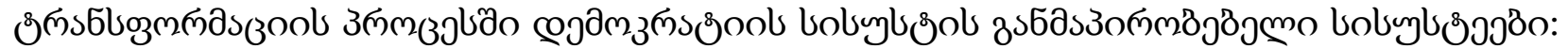

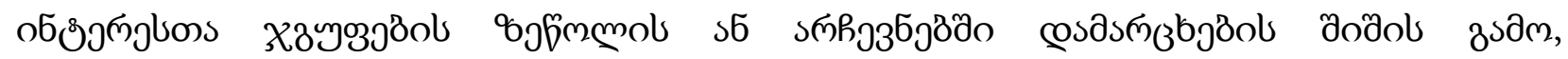

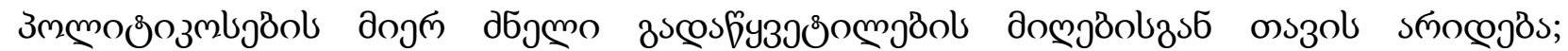

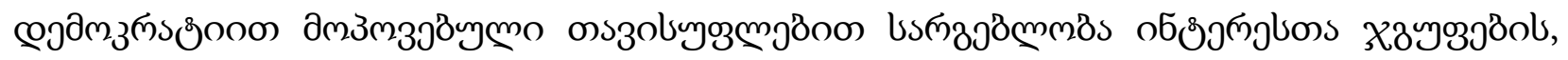

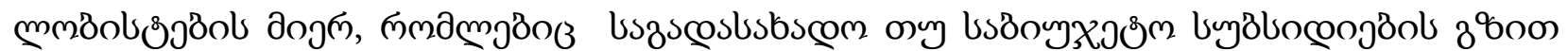

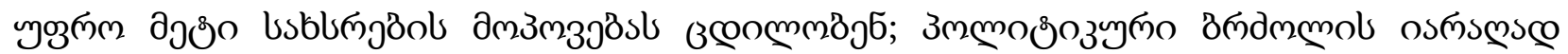

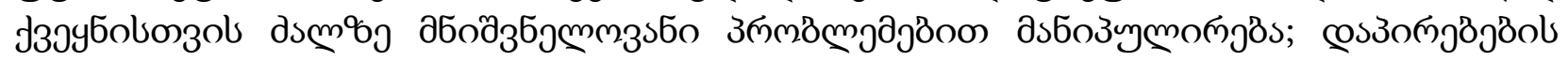

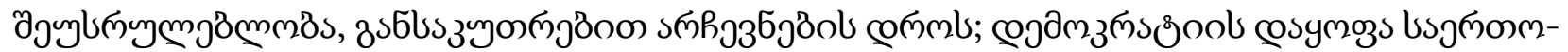

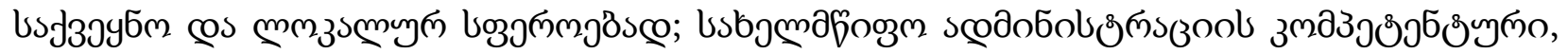

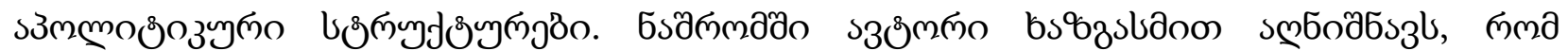

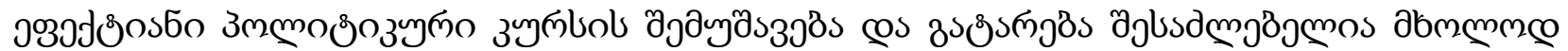

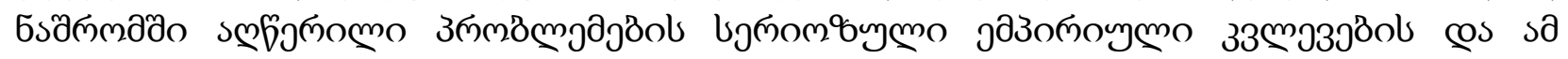

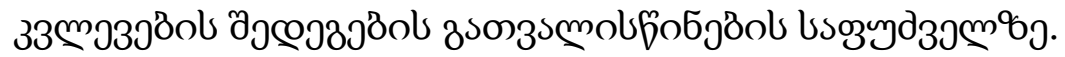

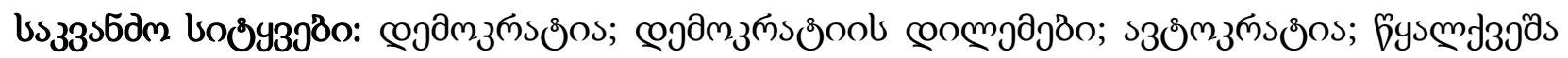

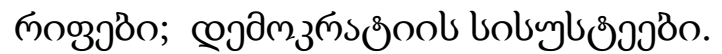

\section{Әjuszsmo}

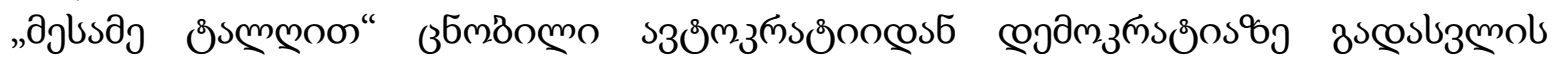

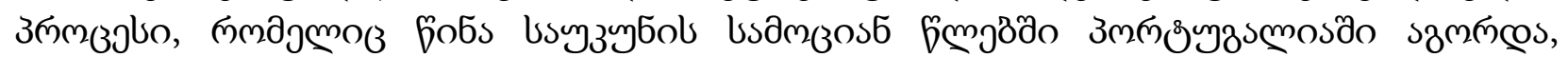

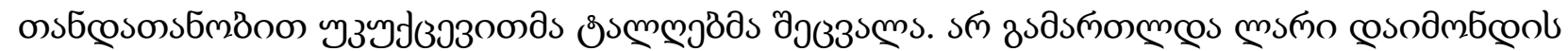

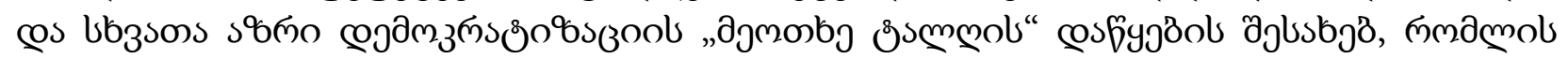

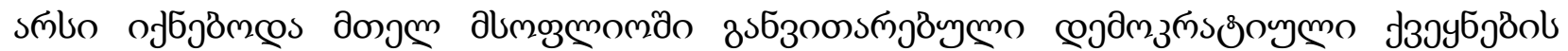

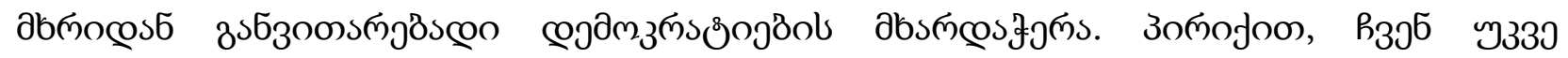

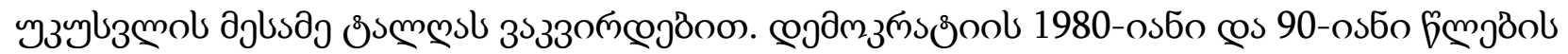

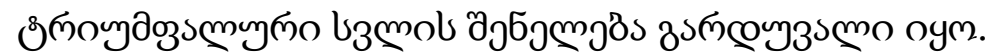

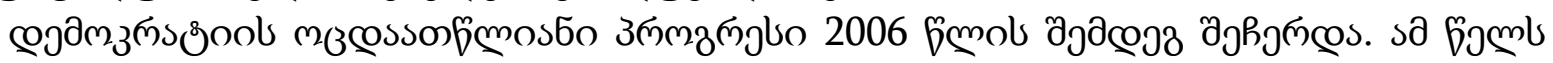

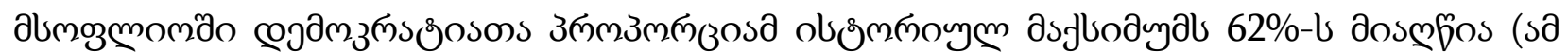

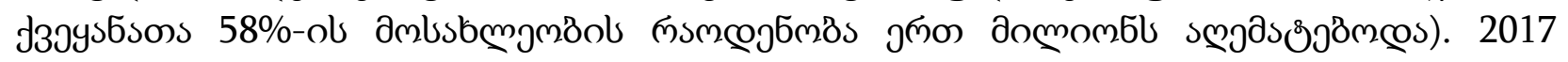

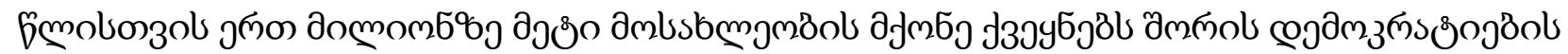

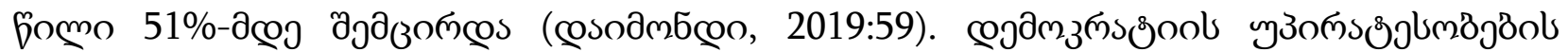




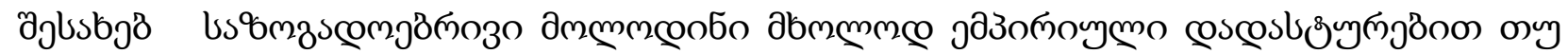

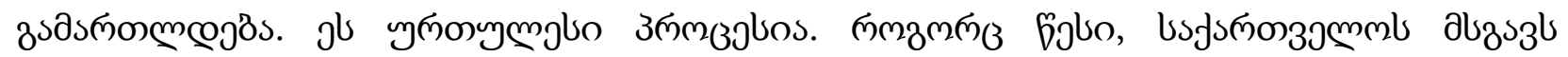

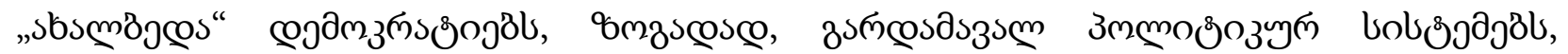

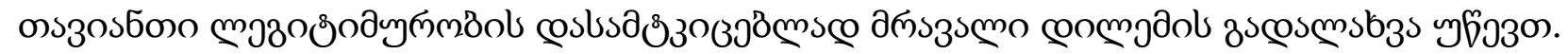

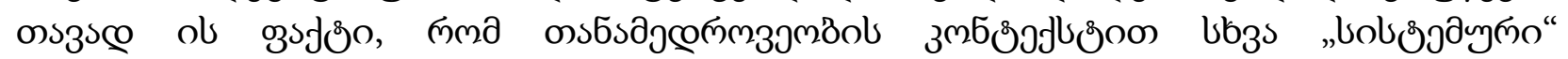

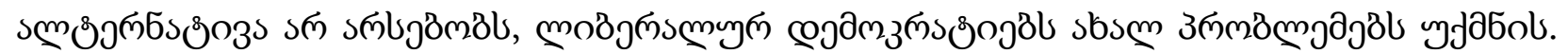

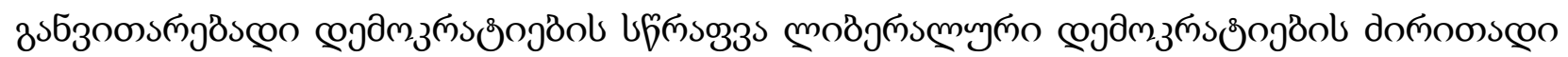

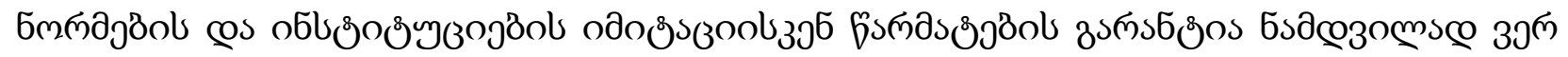

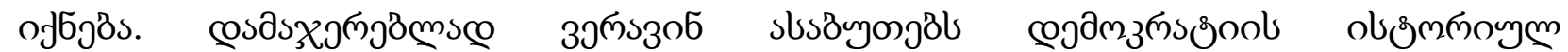

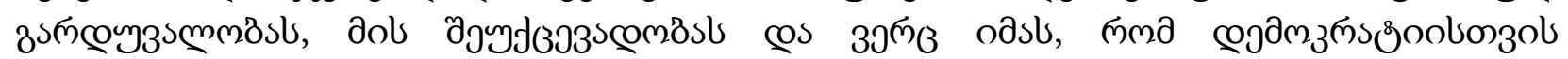

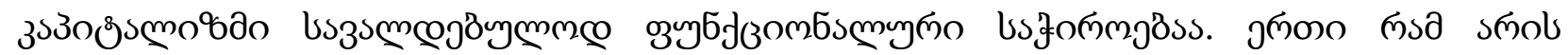

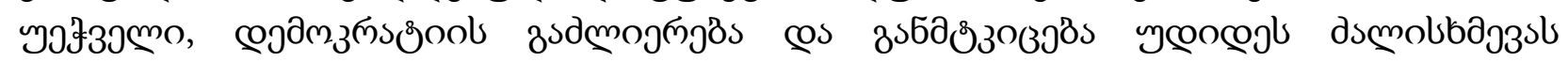

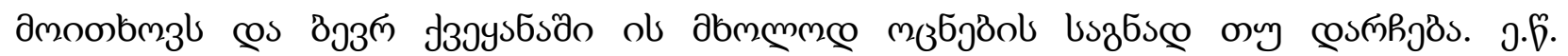

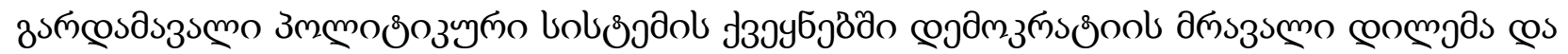
uobyl

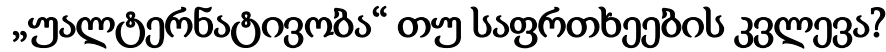

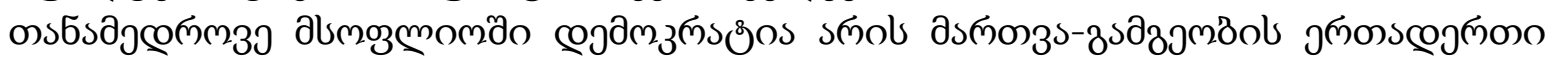

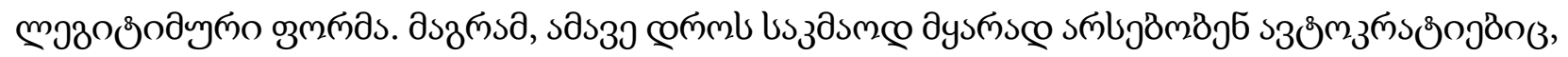

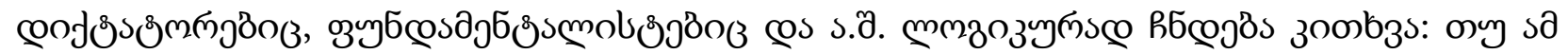

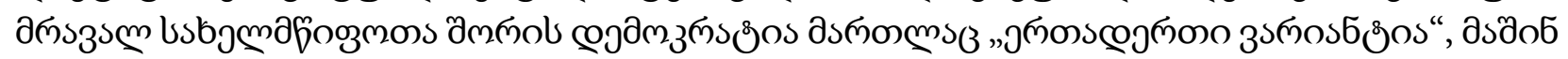

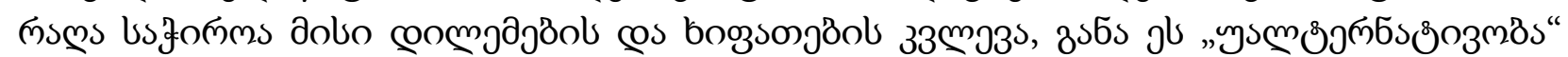

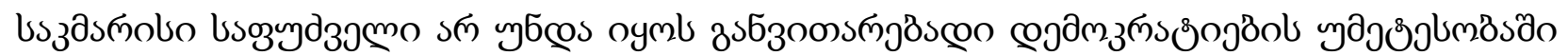

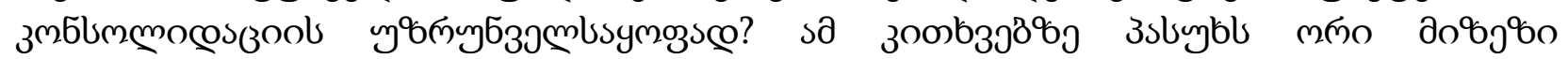

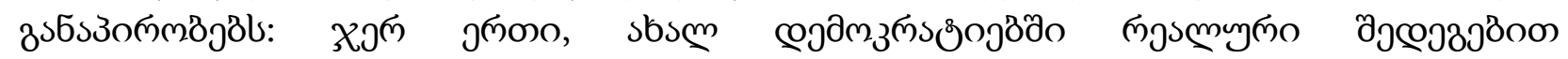

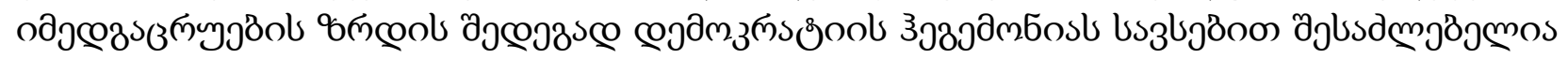

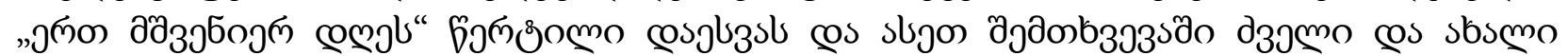

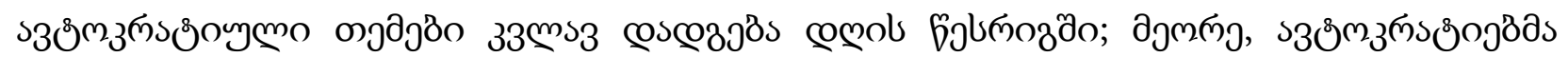

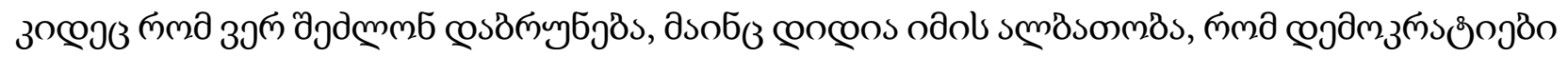

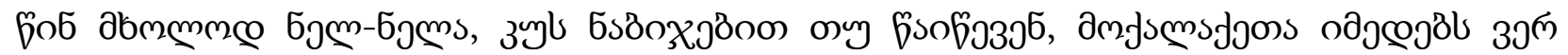

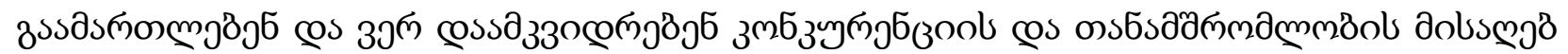

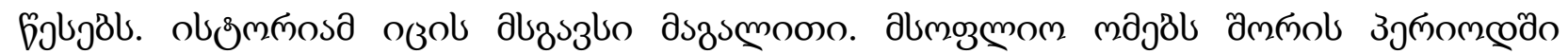

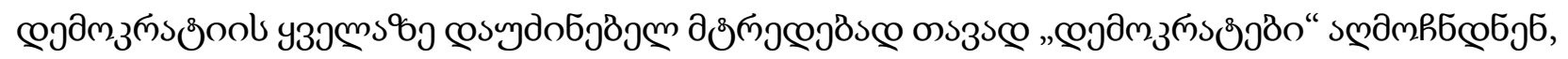

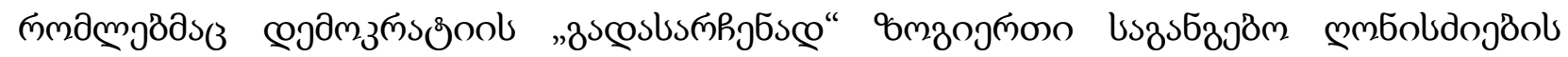

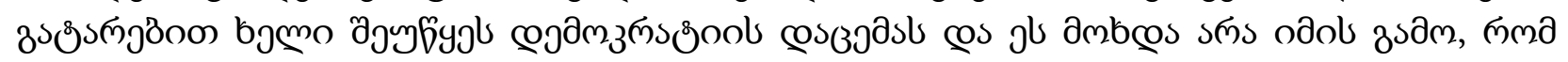

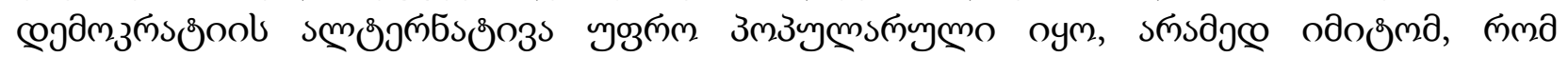

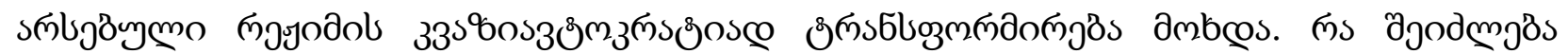

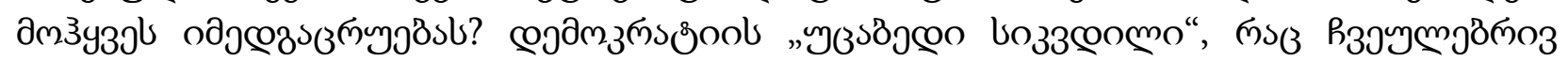

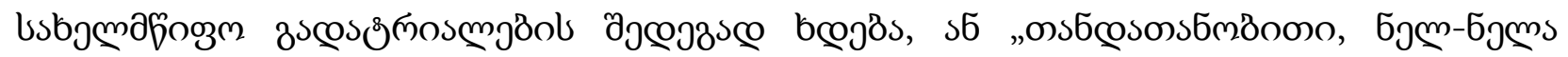

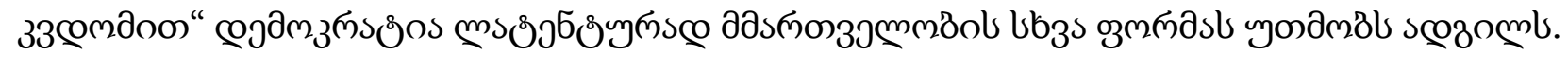

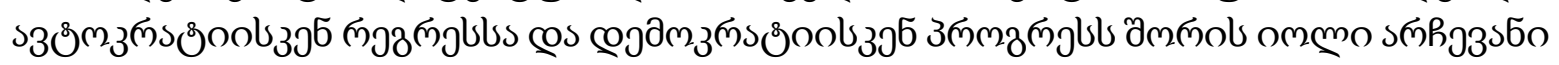

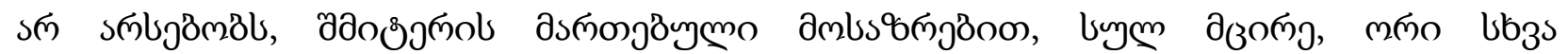

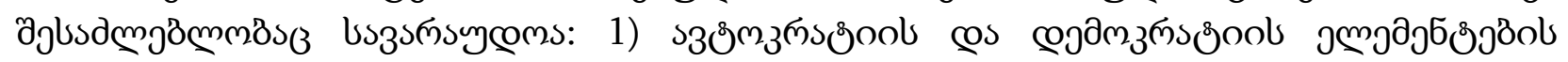

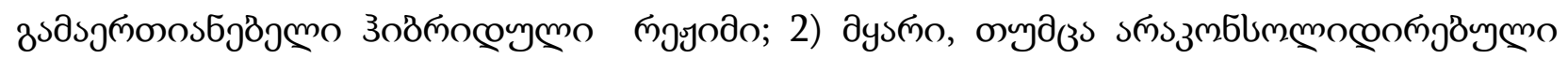

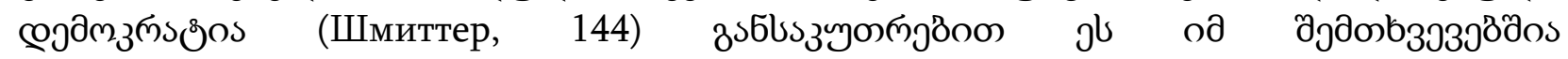

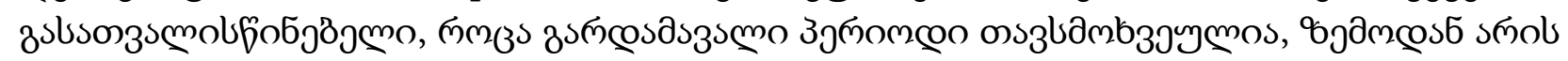

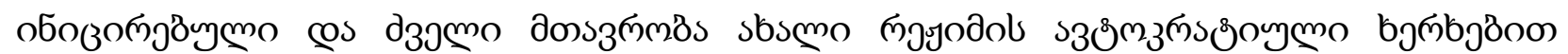




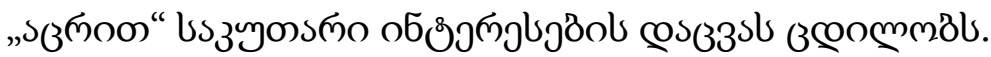

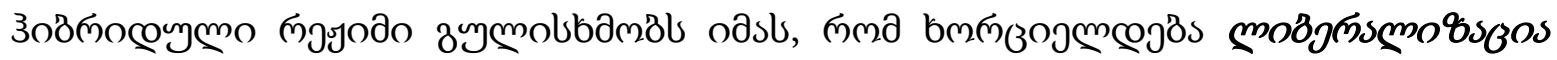

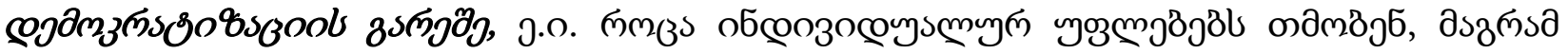

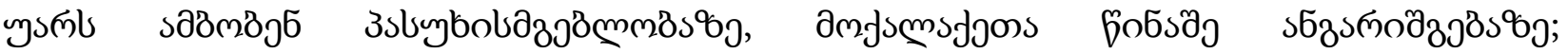

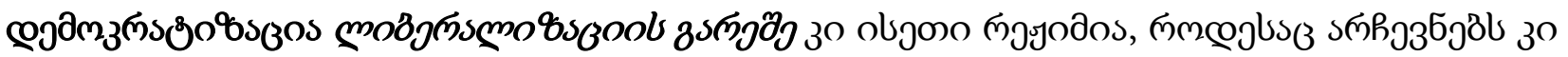

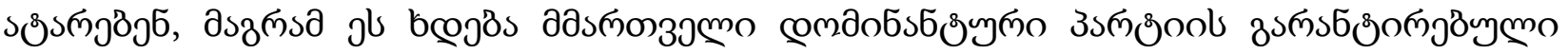

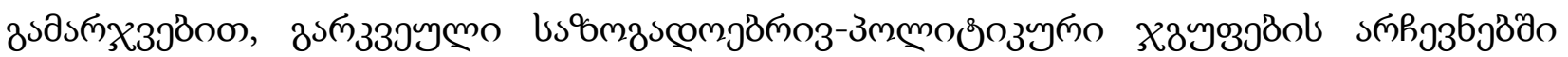

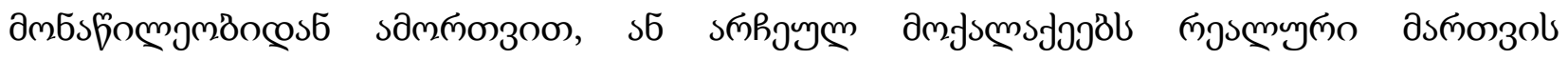

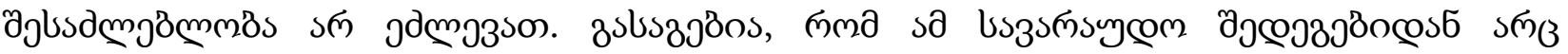

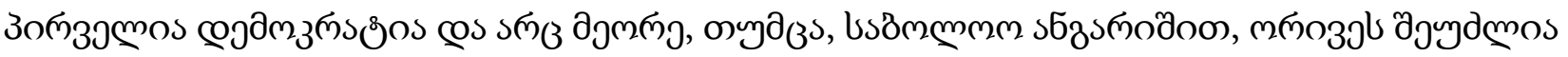

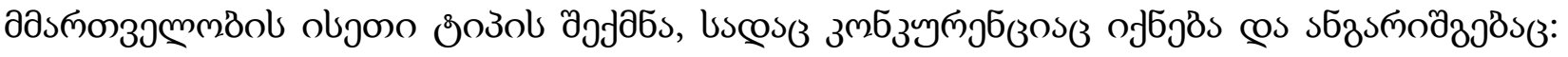

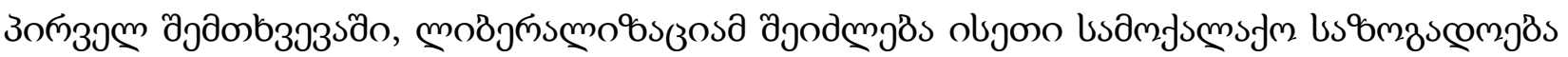

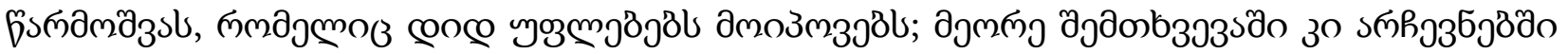

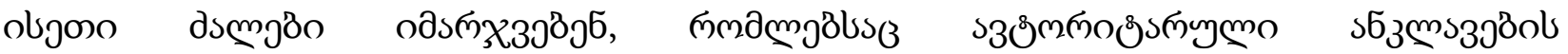

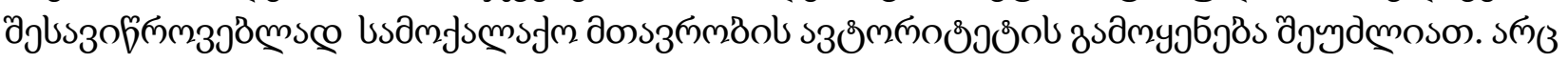

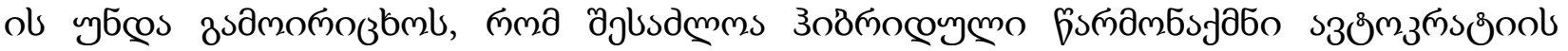

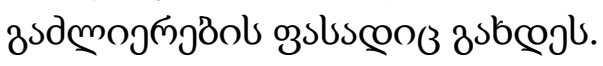

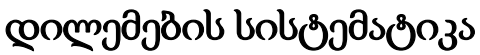

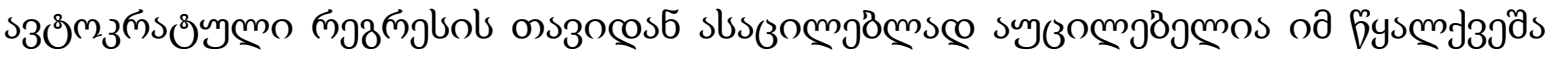

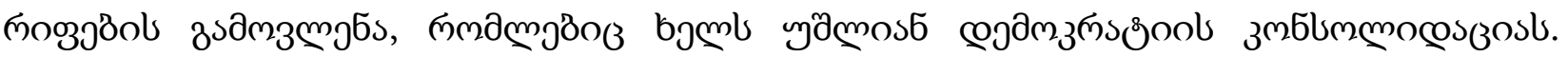

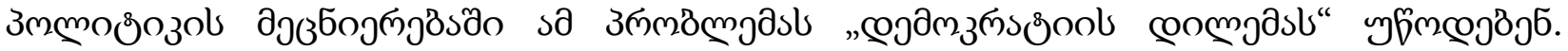

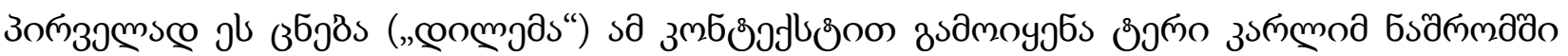

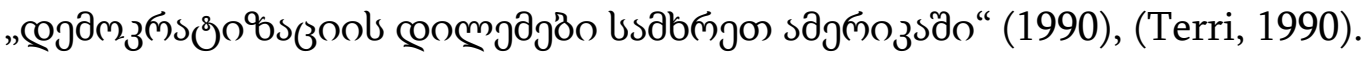

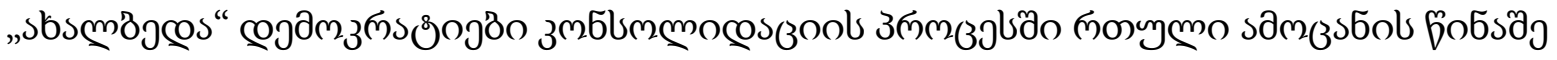

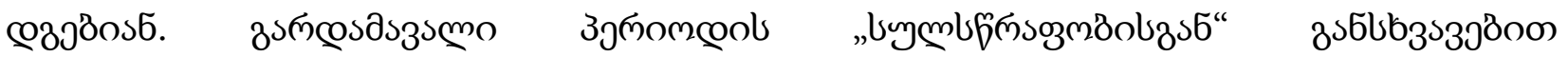

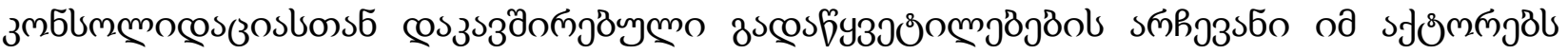

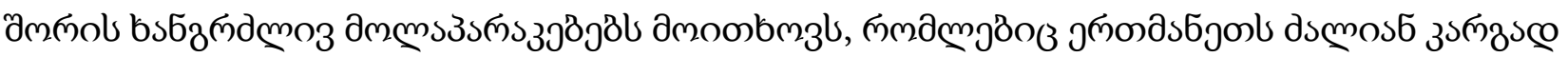

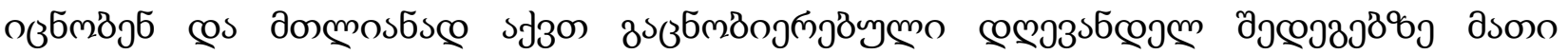

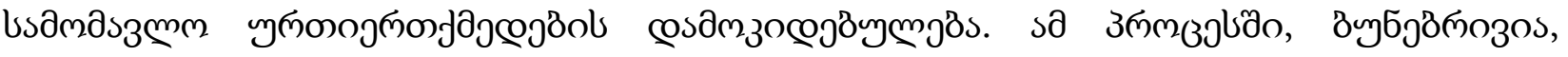

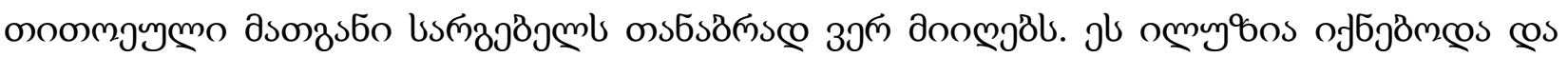

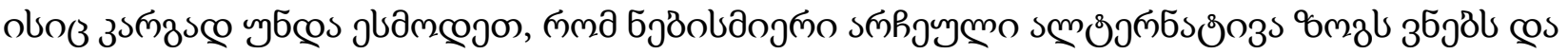

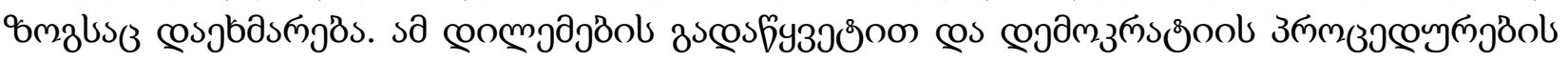

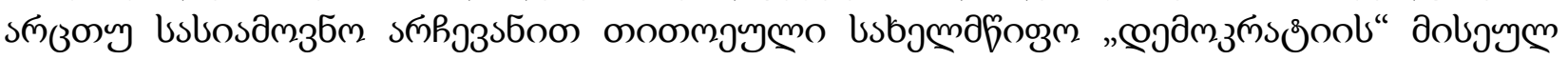

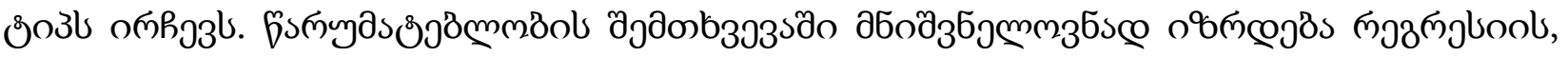

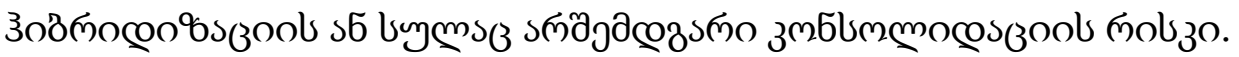

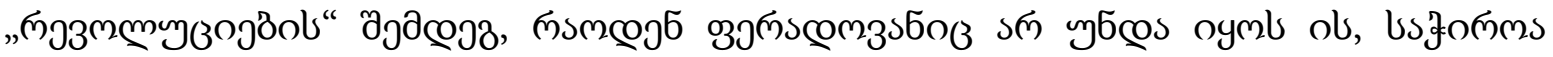

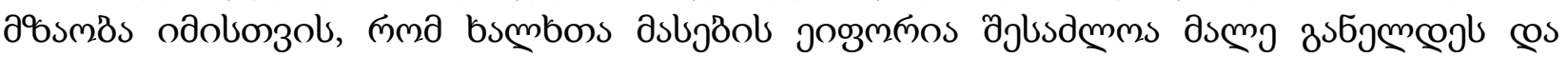

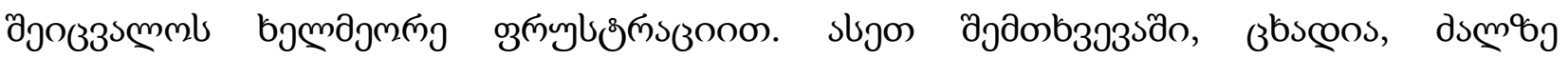

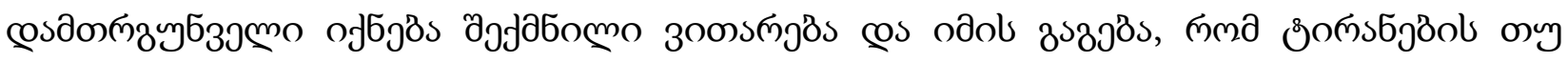

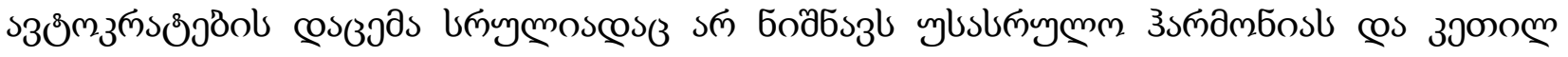

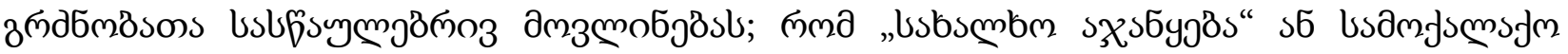

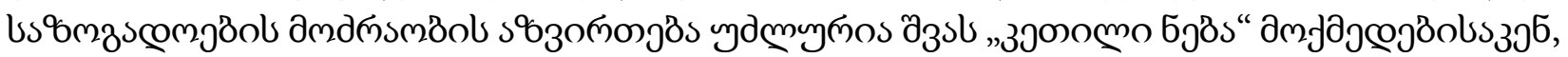

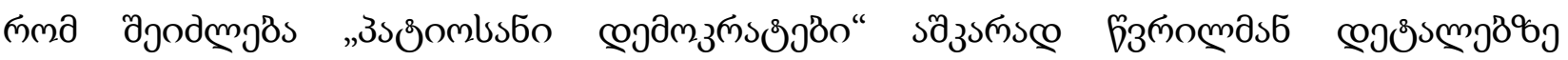

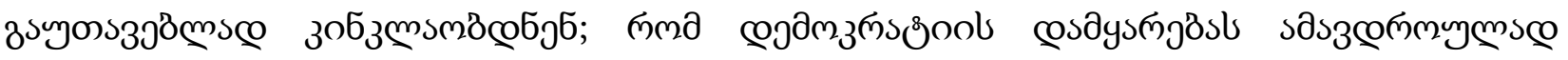

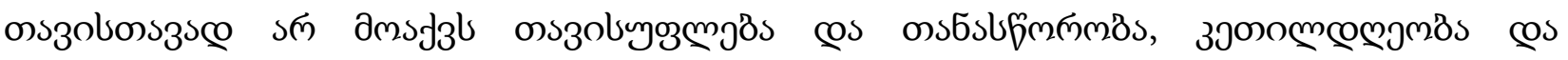

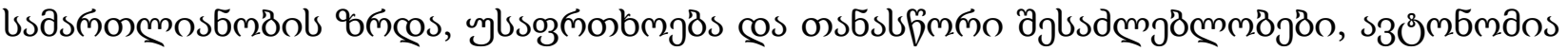




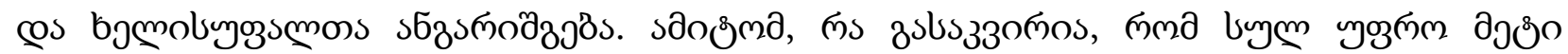

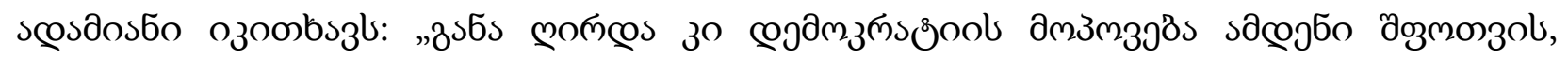

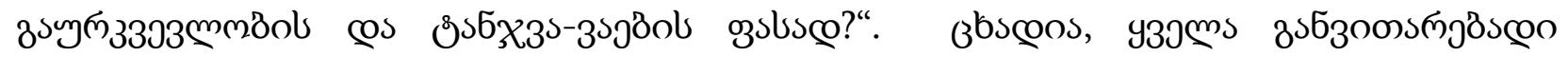

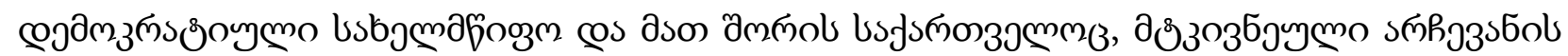

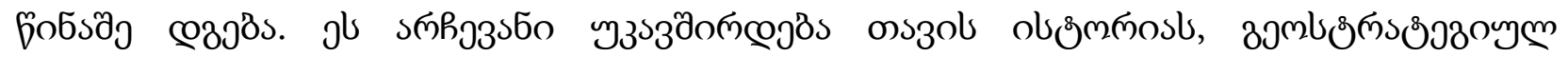

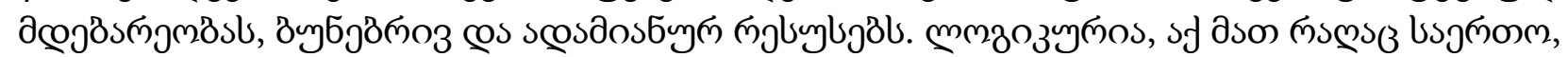

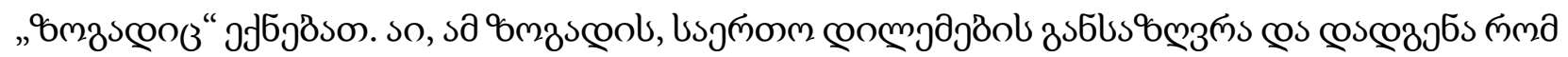

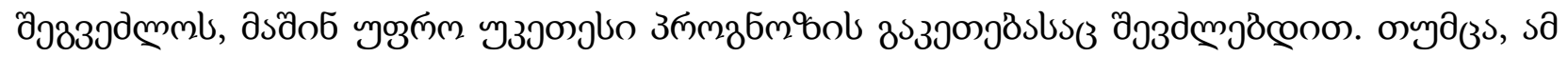

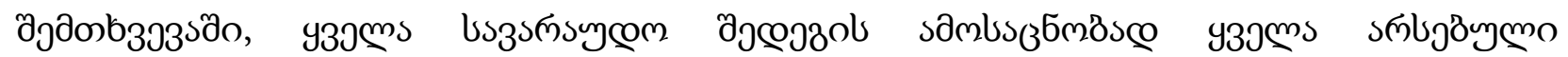

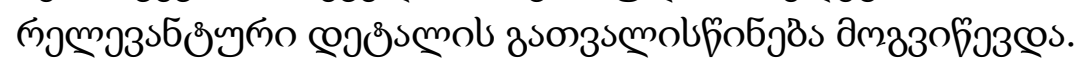

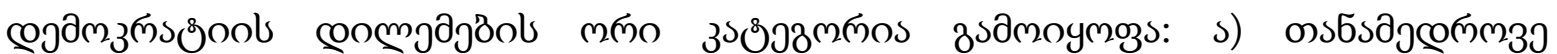

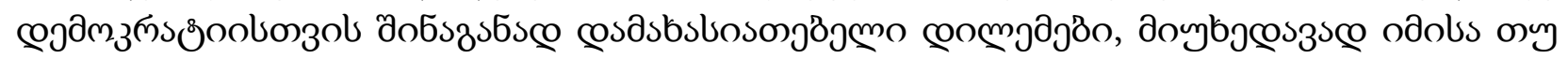

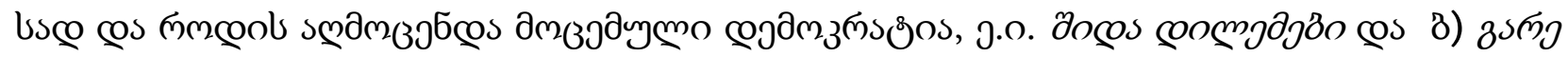

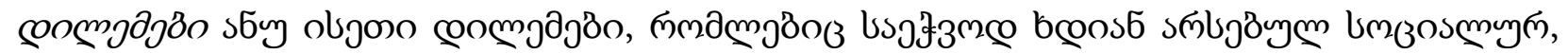

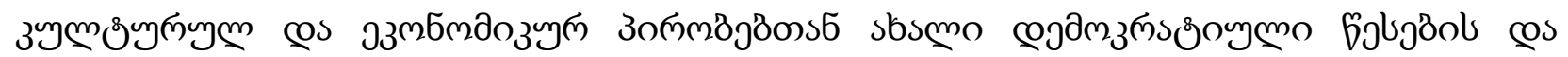

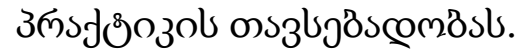

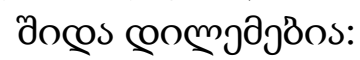

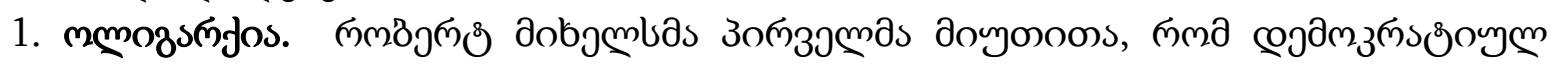

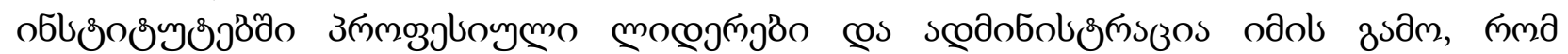

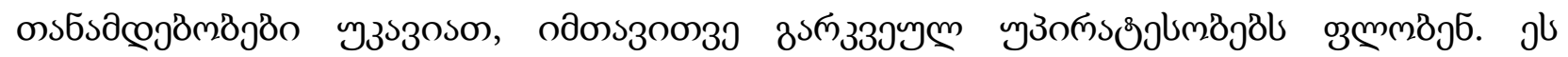

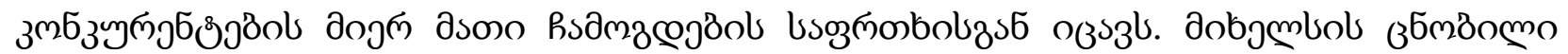

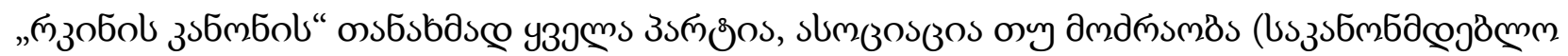

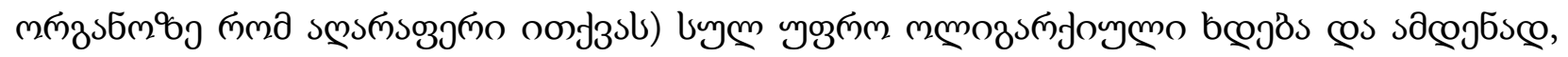

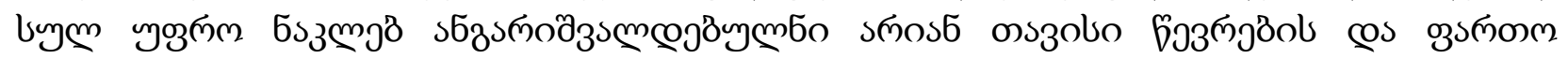
us\%mzscomgöol foбsð̃ (Michels, 1962).

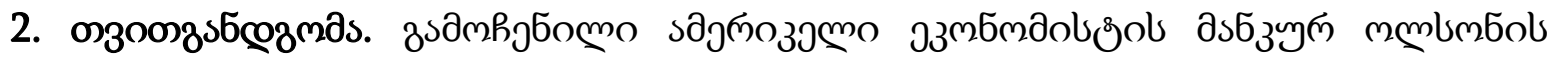

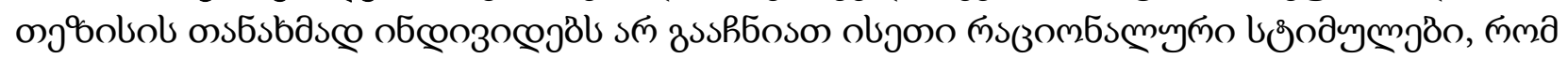

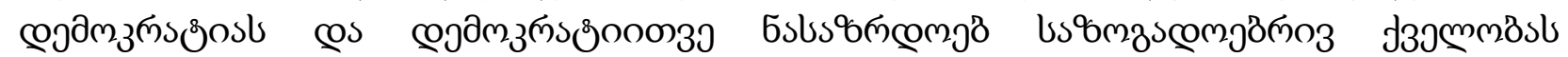

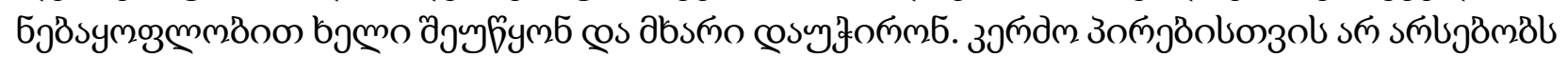

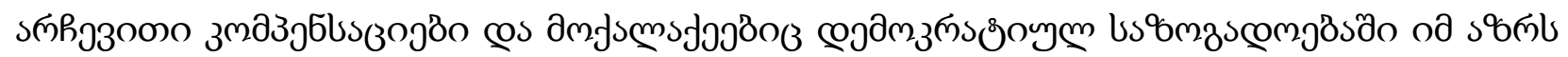

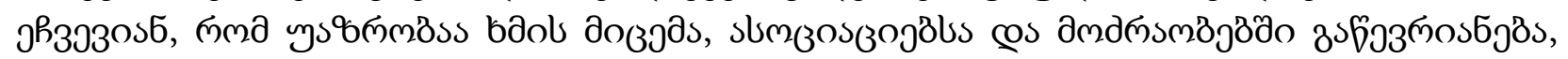

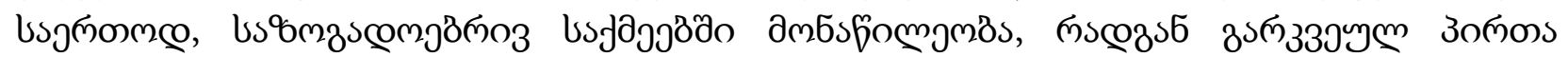

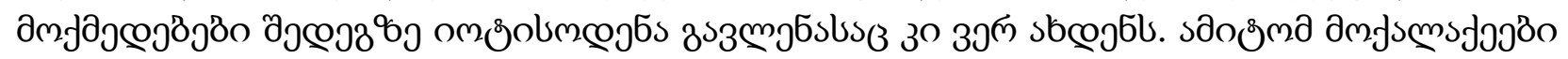

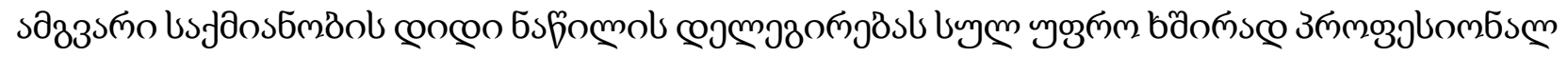

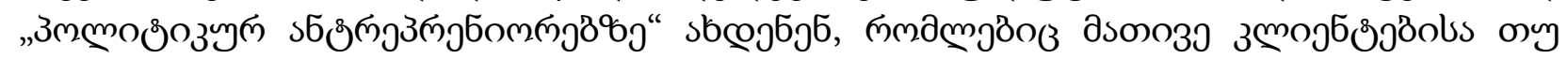

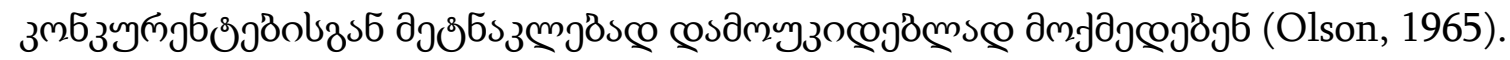

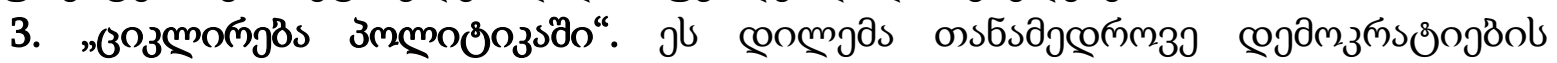

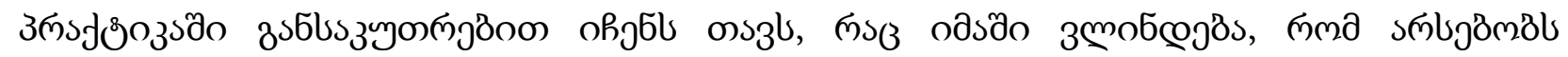

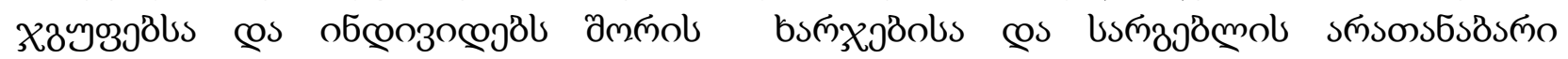

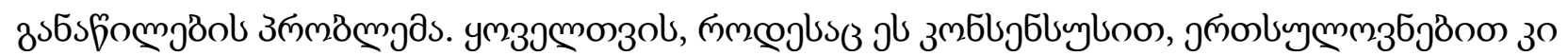

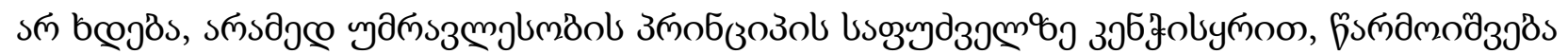

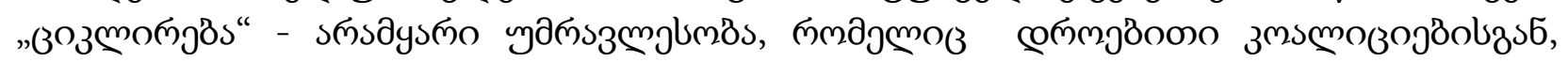

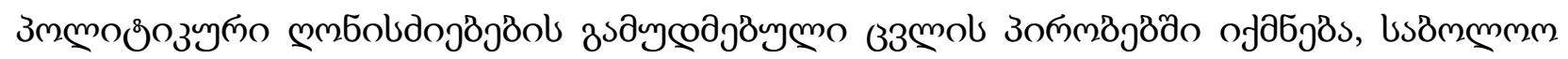

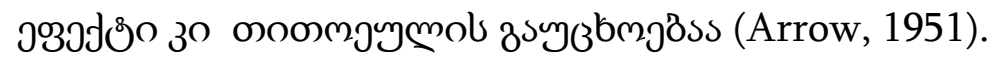

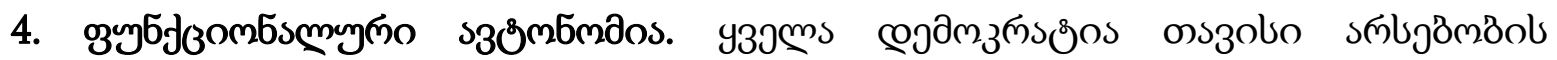

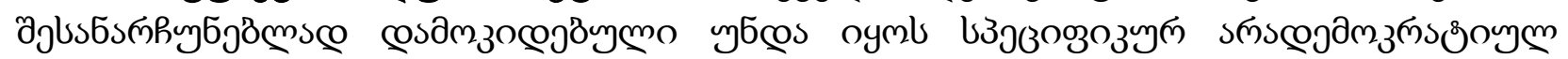




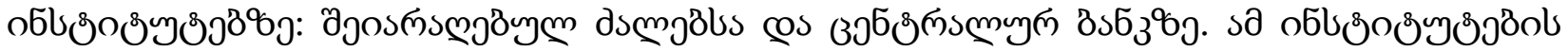
э

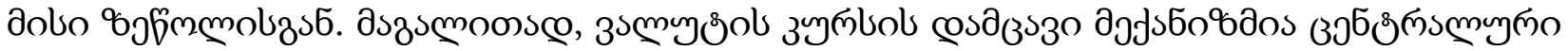

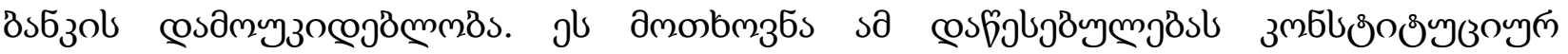

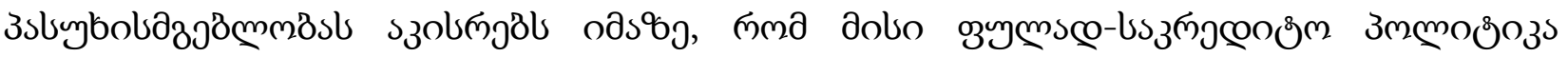

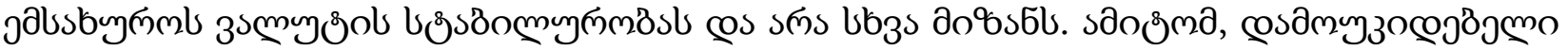

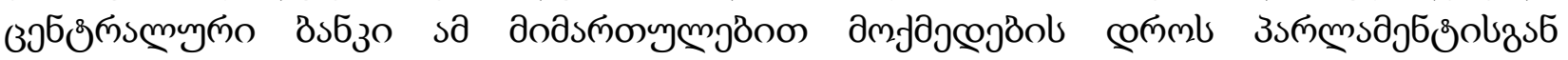

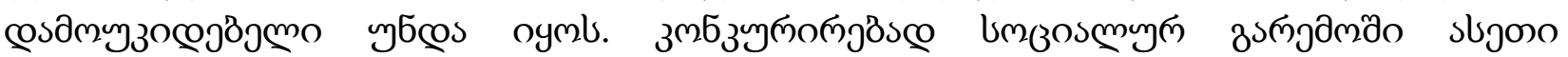

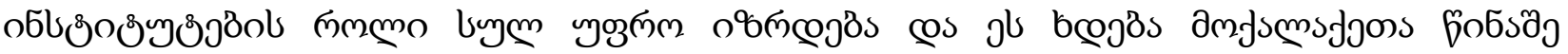

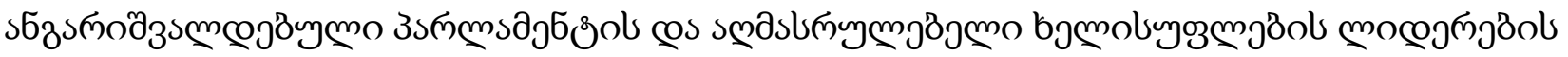
bsलxisy.

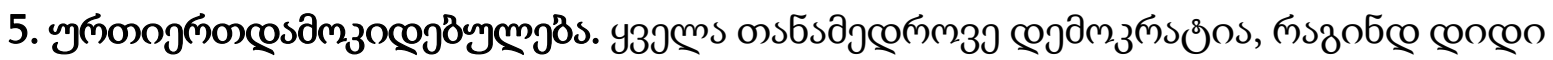

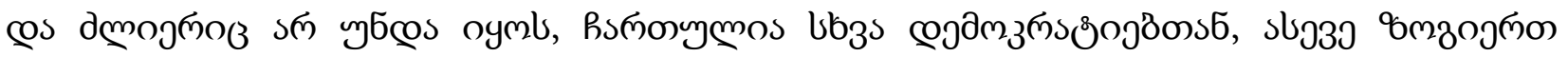

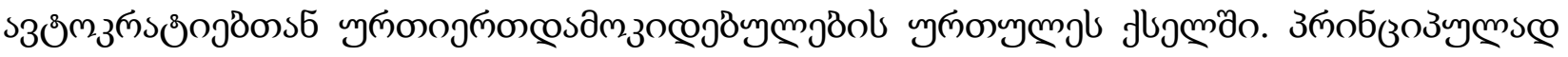

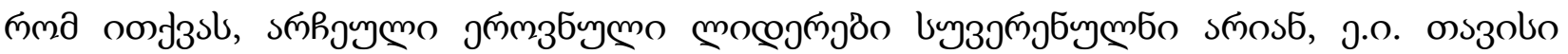

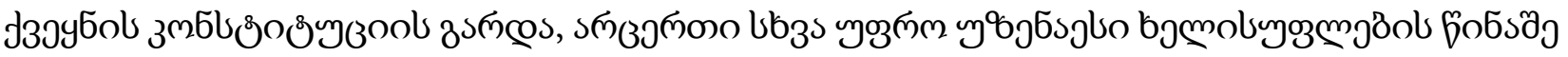

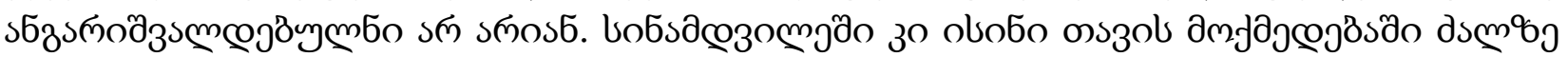

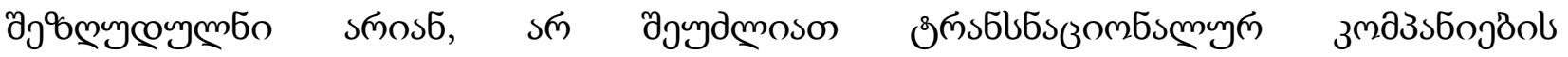

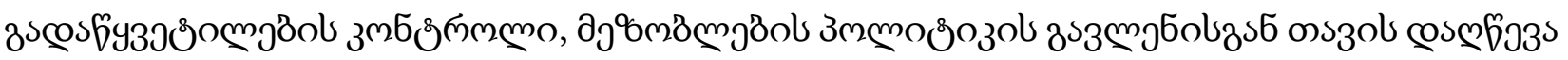

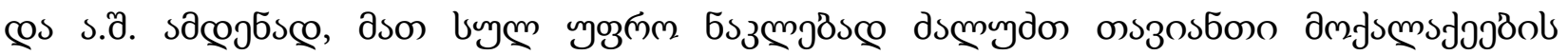

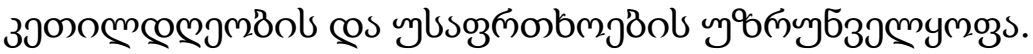

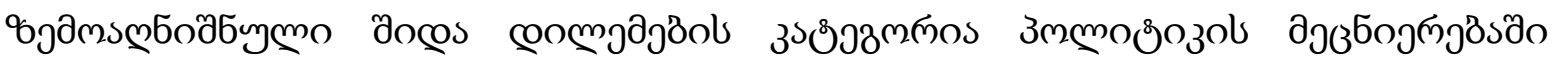

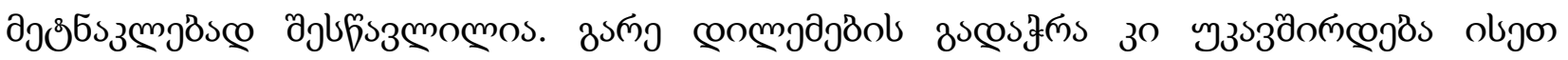

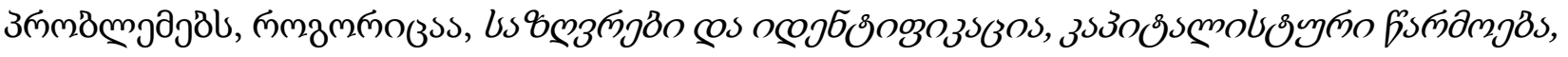

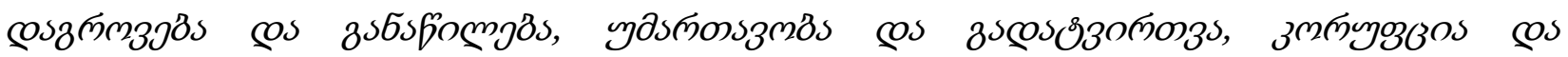

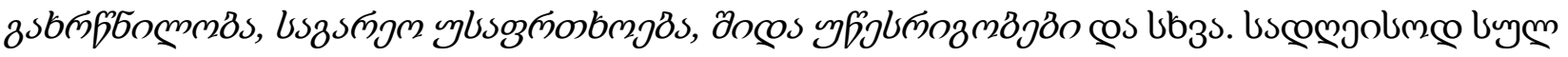
ээґм опе об

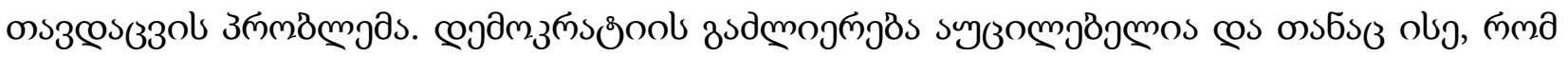

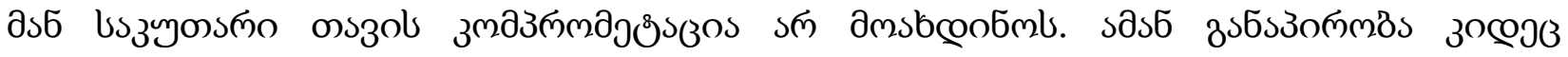

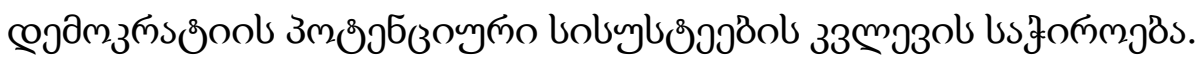

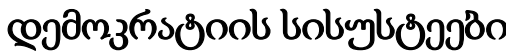

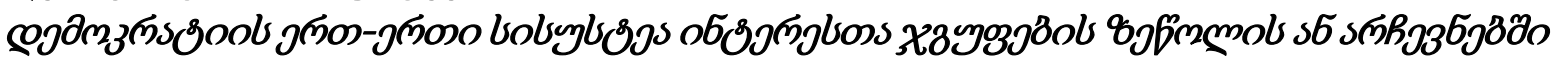
cosasm (b)

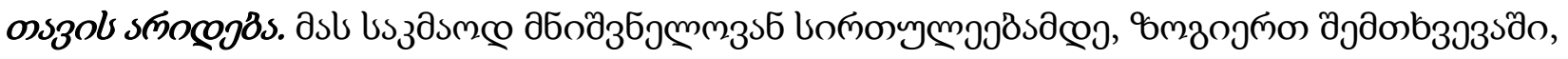

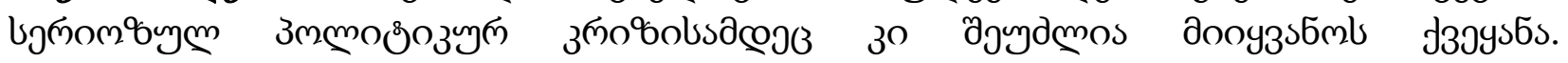

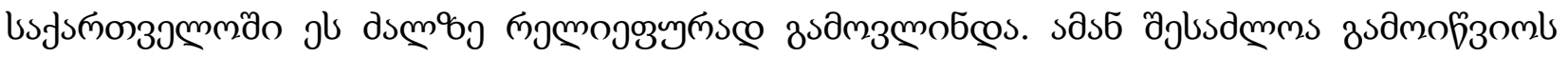

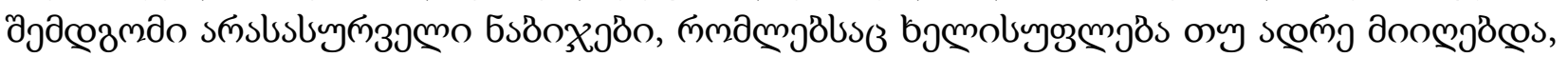

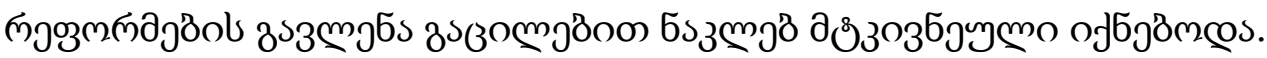

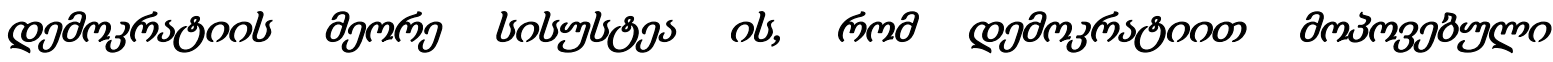

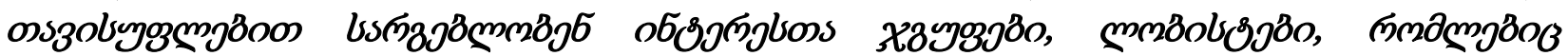

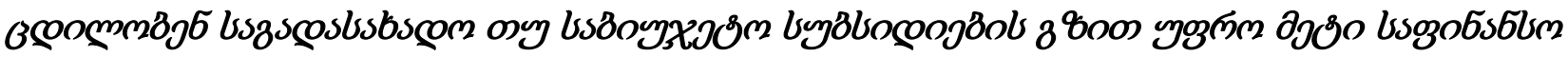

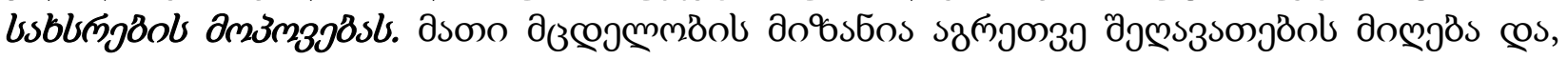

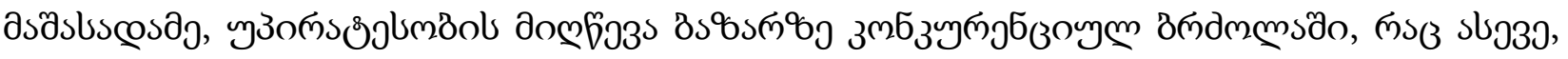

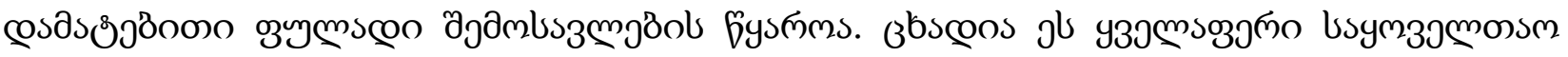

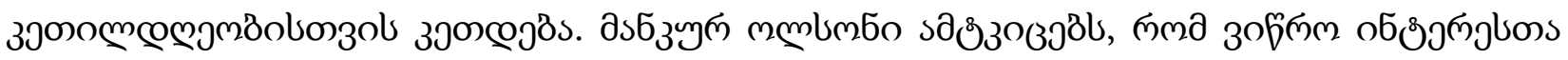

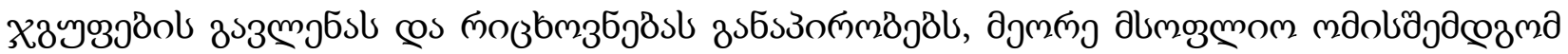




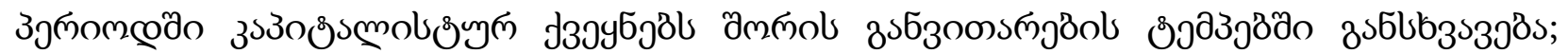

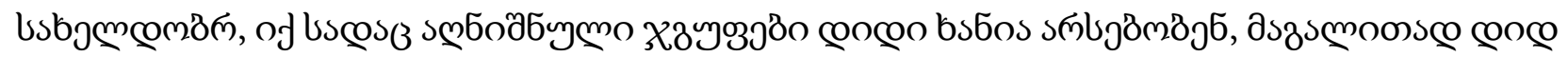

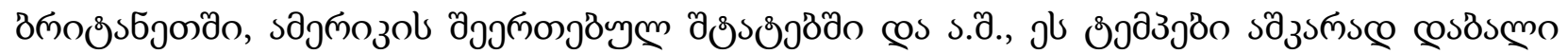

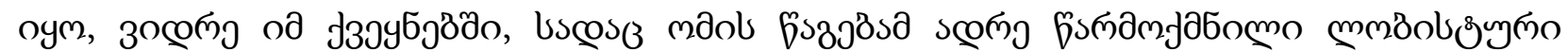

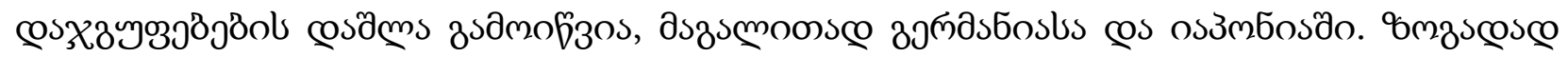

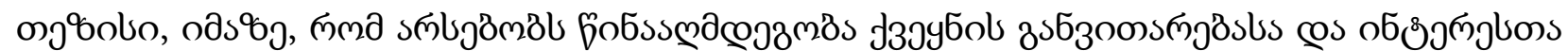

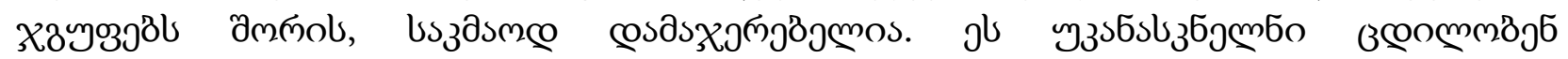

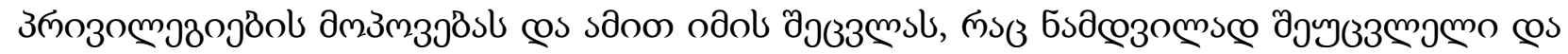

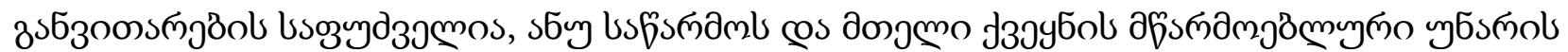

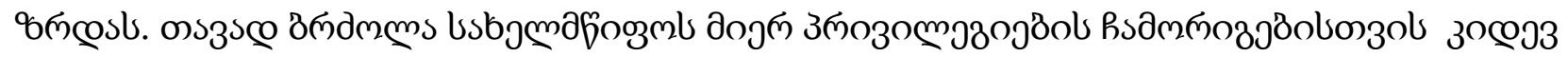

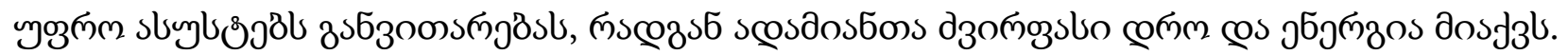

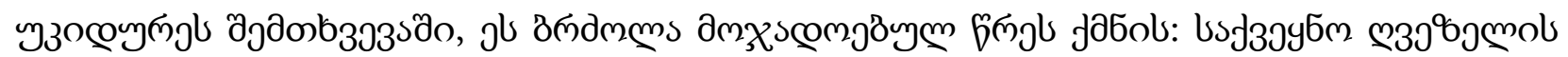

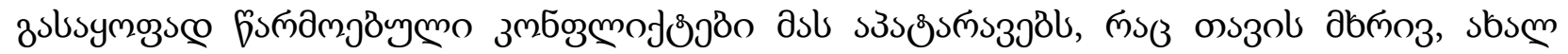

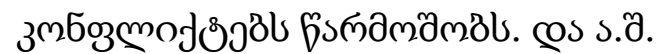

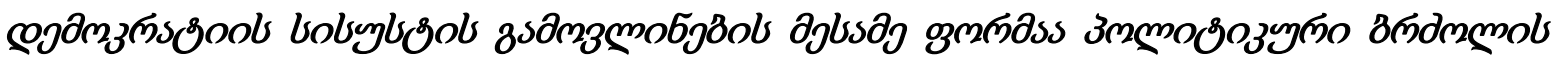

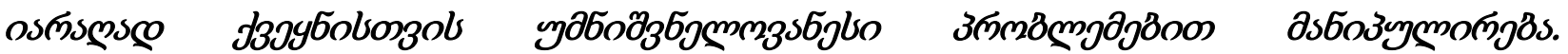

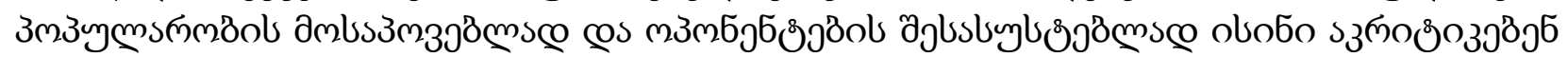

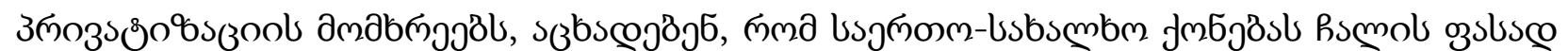

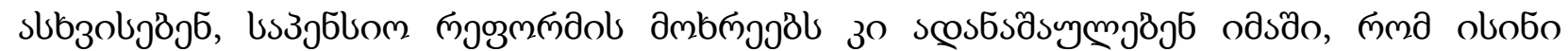

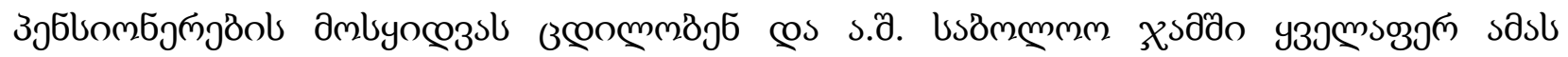

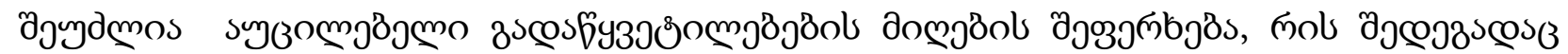

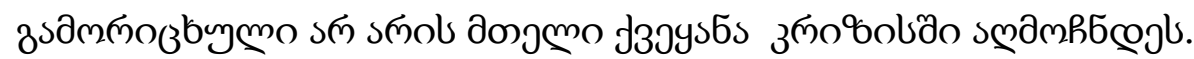

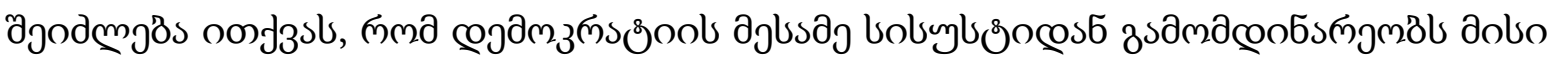

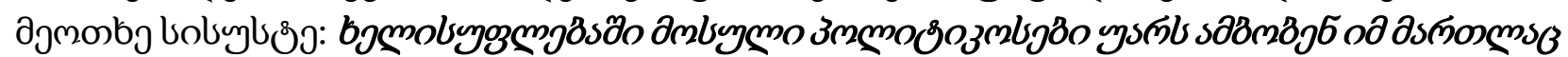

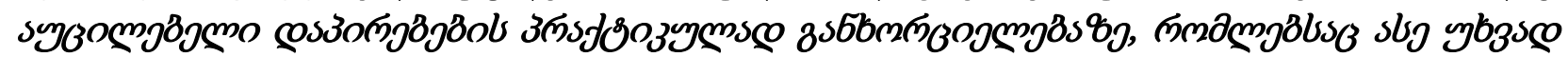

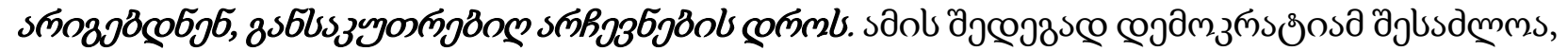

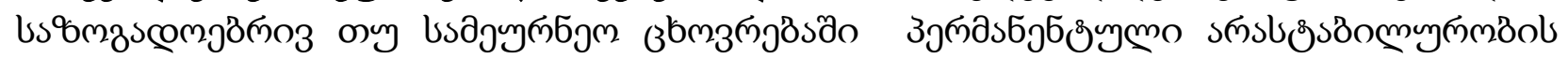

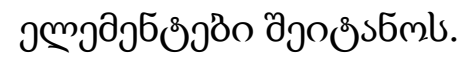

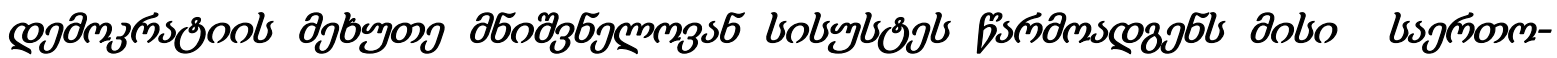

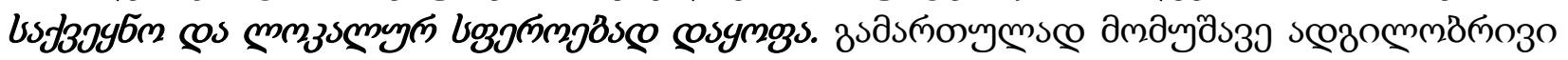

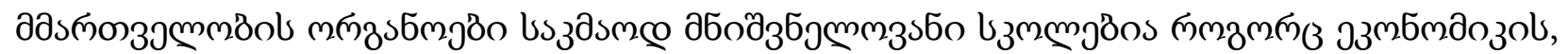

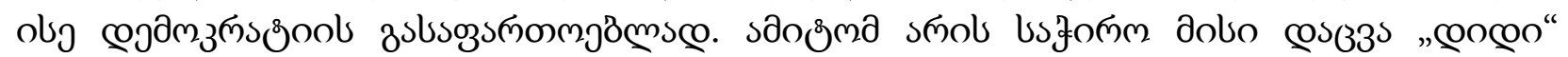

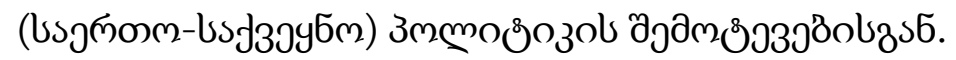

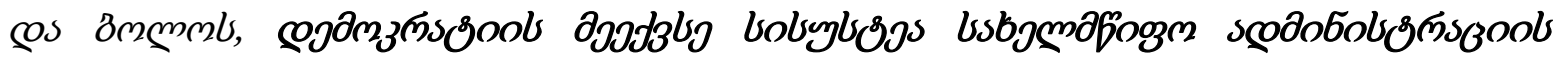

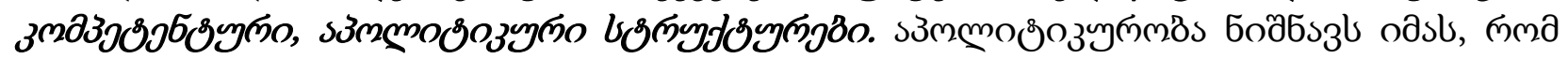

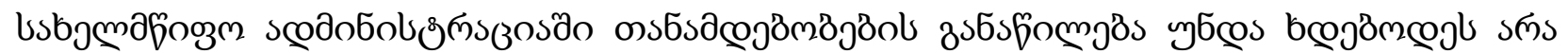

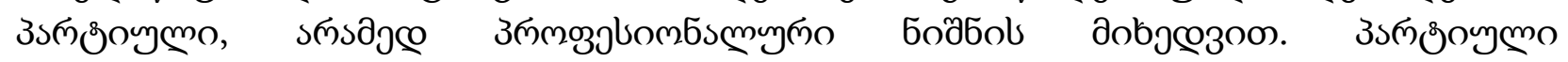

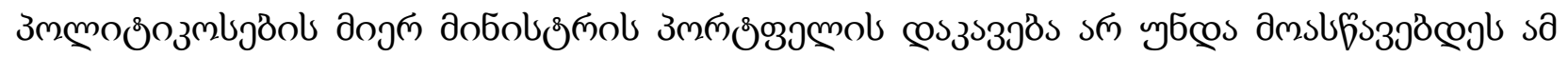

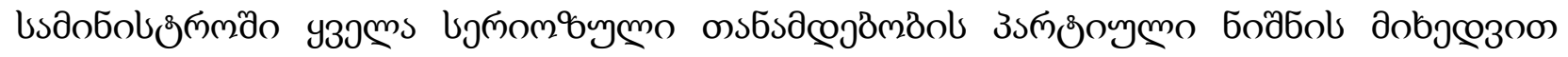
zsбsfomgiss.

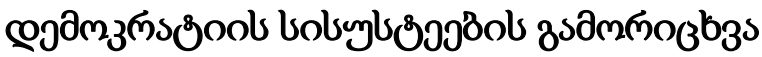

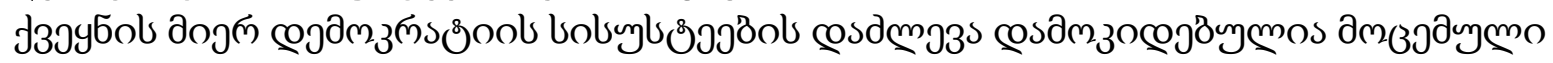

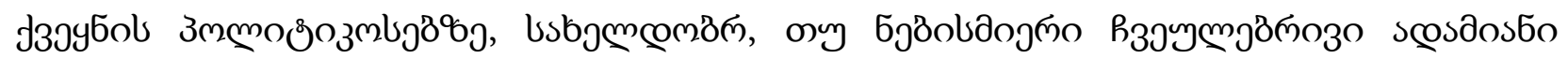

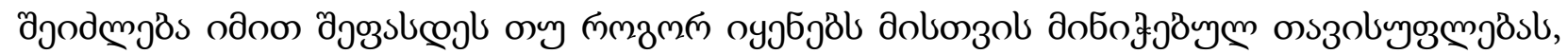

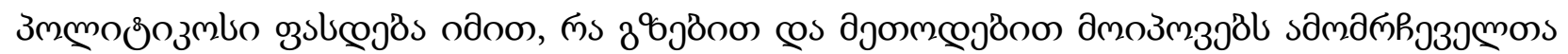

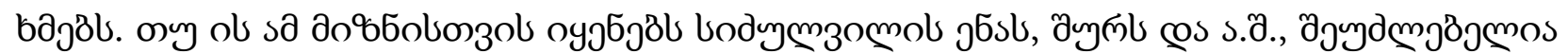




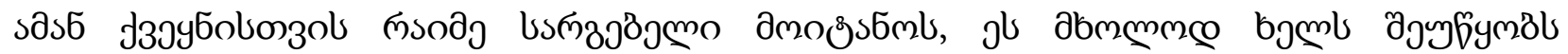

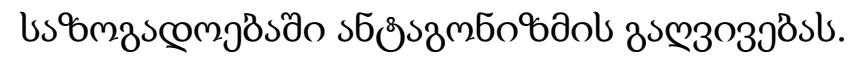

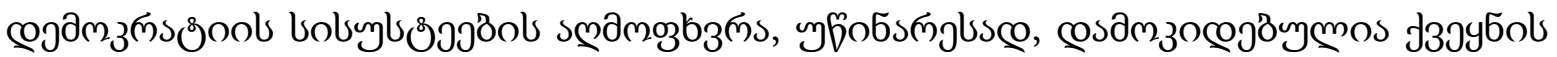

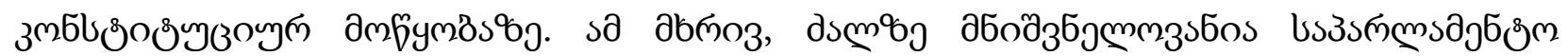

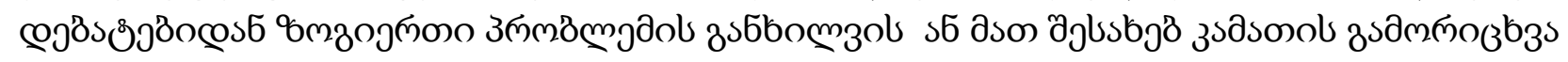

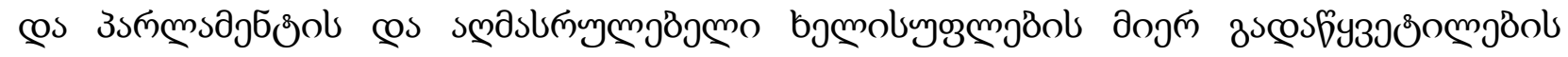

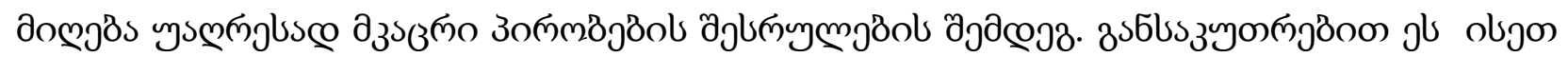

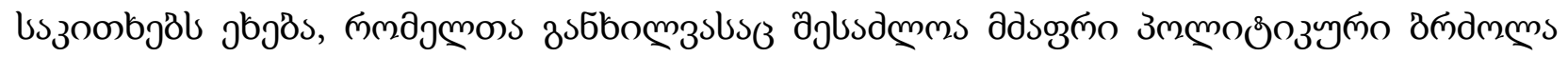

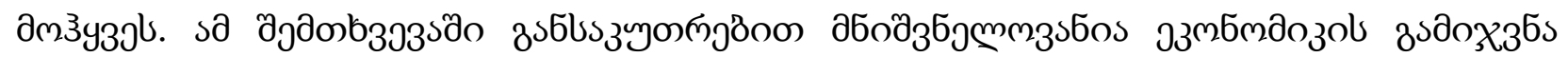

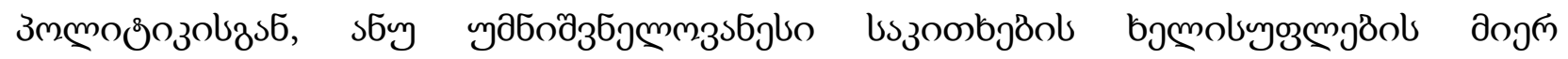

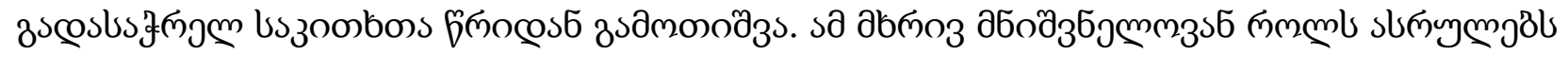

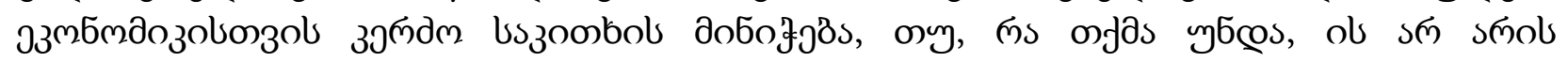

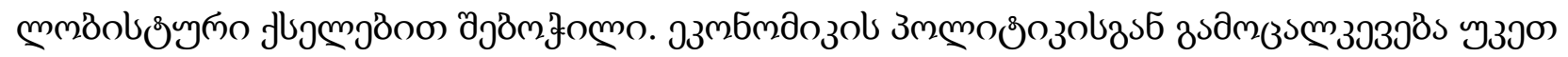

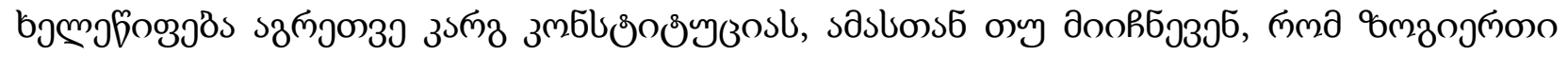

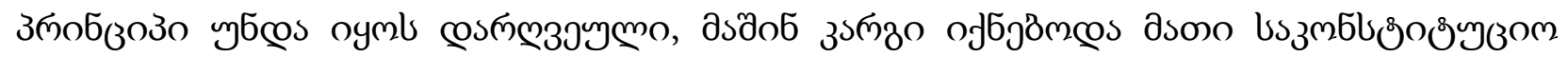

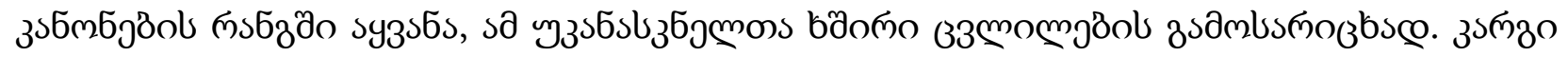

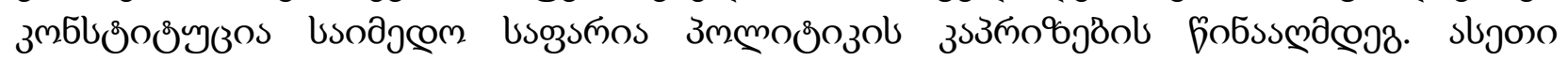

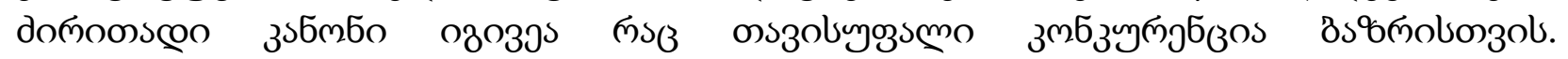

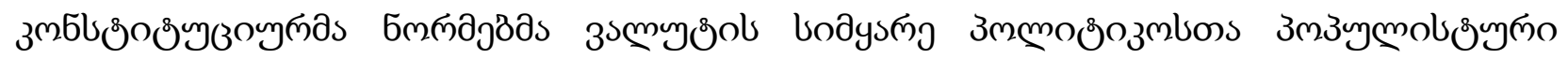

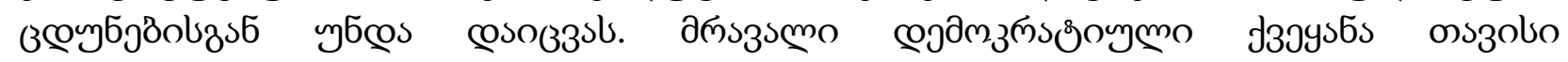

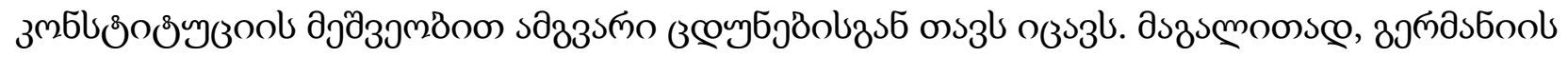

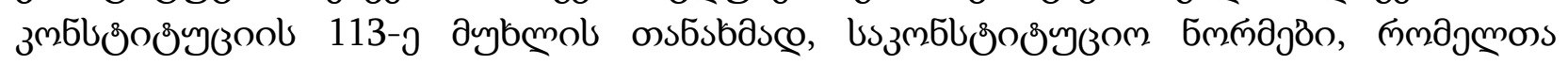

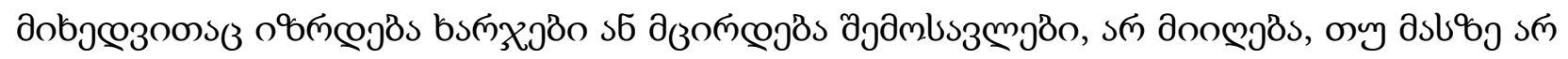

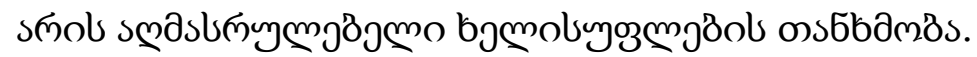

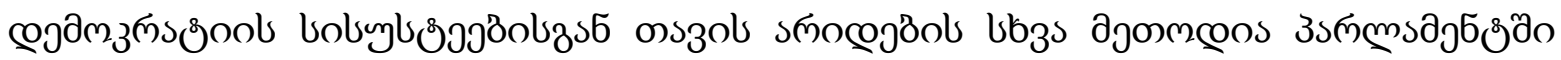

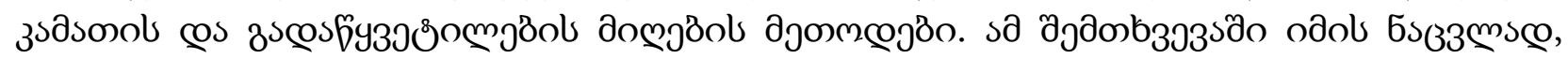

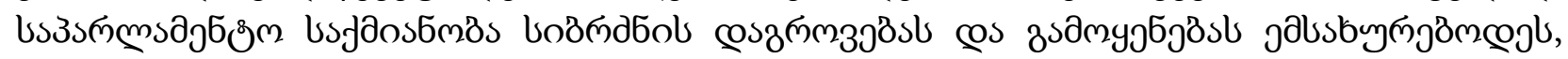

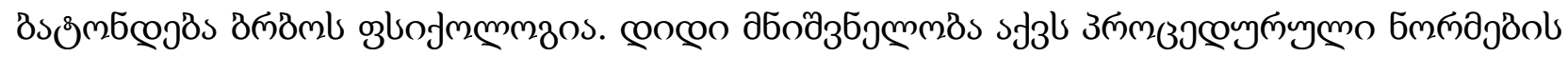

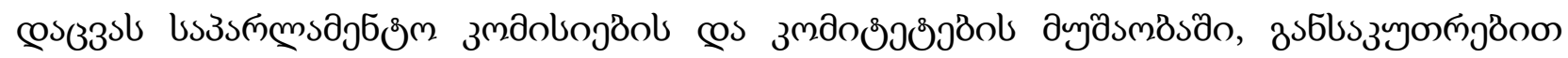

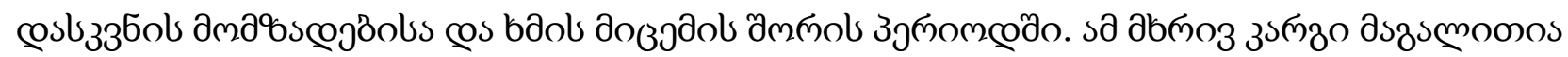

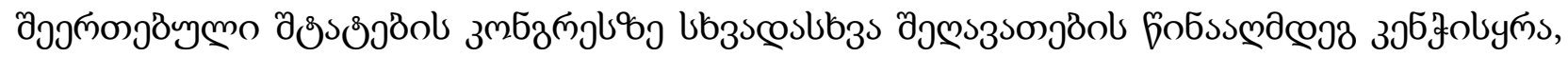

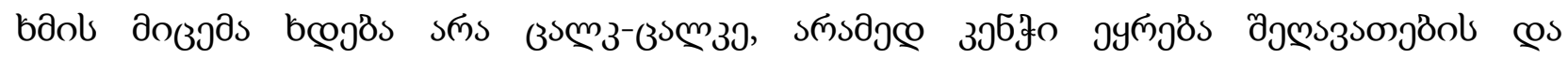

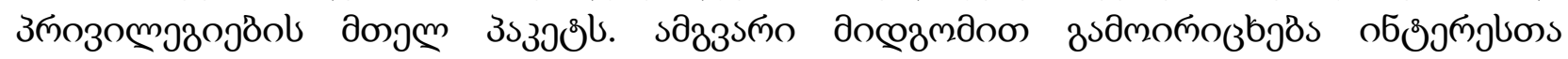

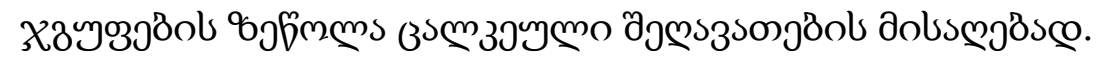

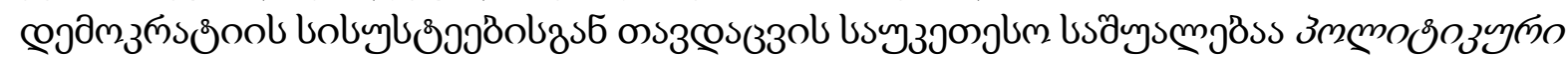

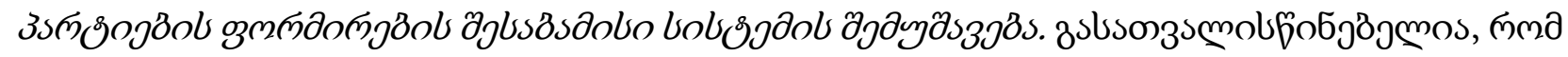

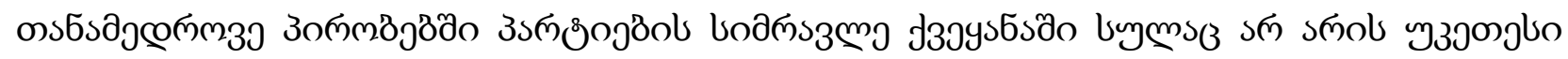

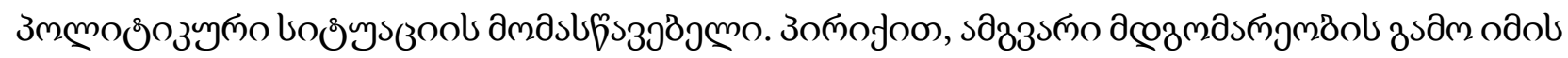

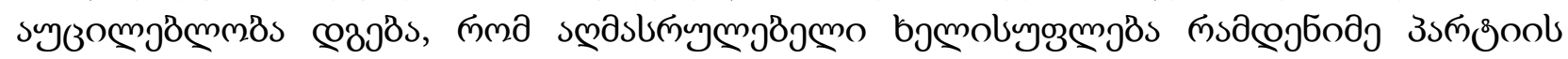

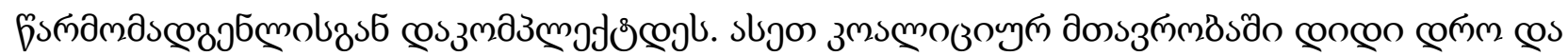

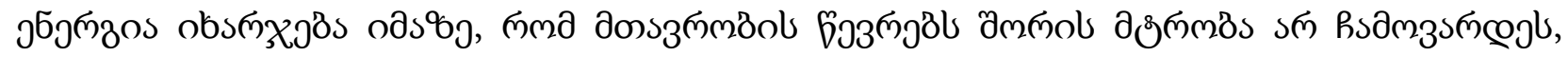

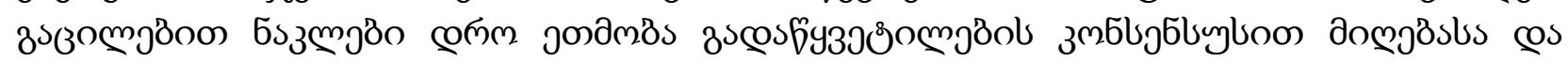

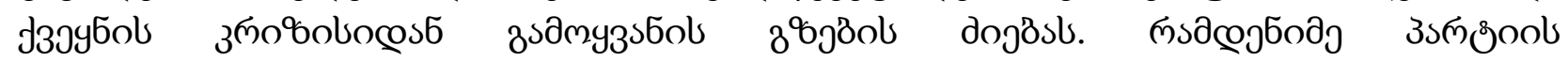

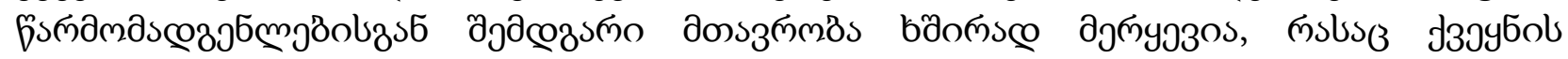

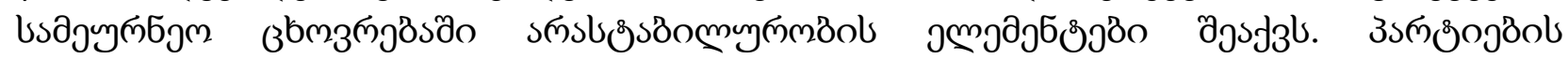

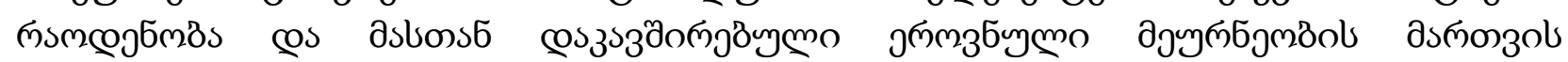




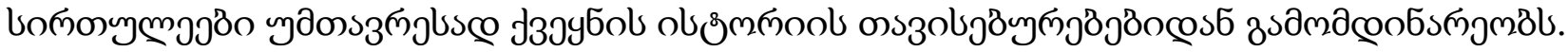

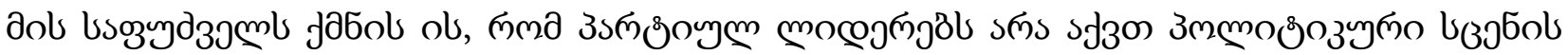

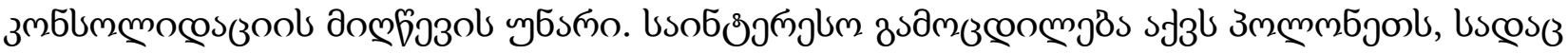

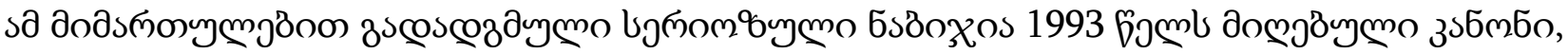

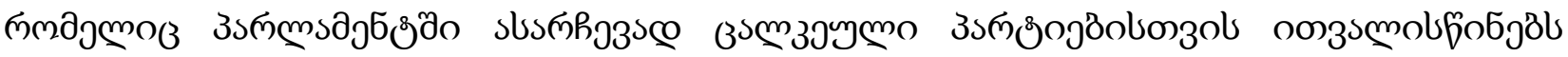

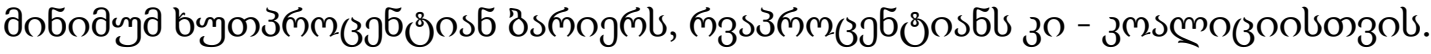

\section{cosl 3365}

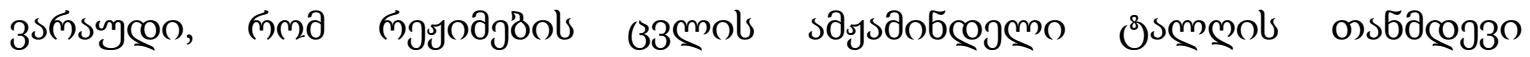

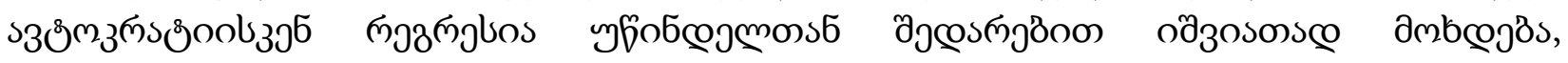

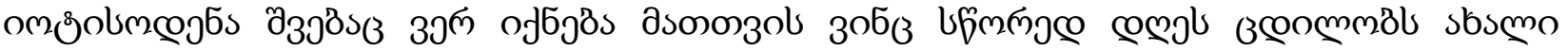

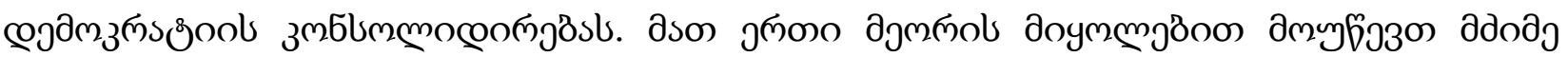

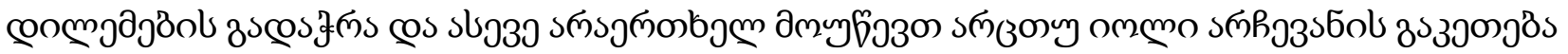

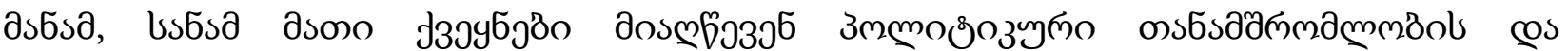

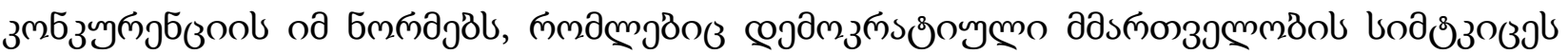

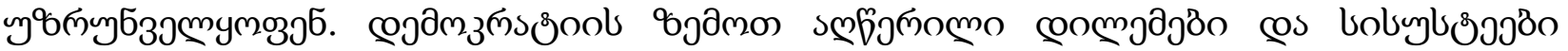

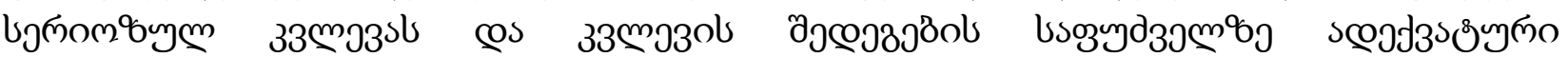

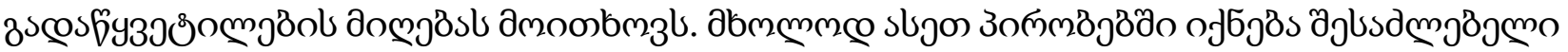

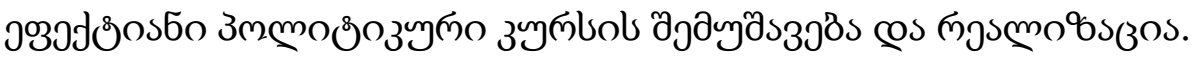

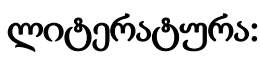

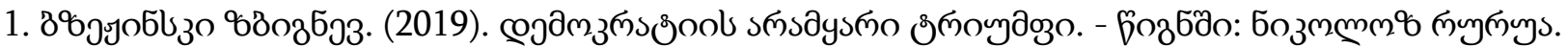

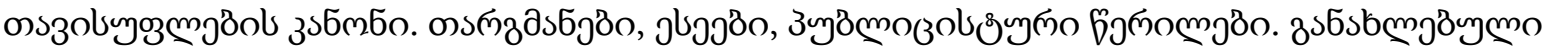

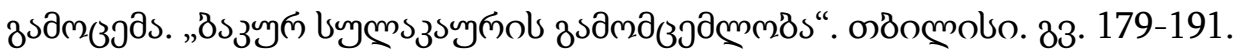

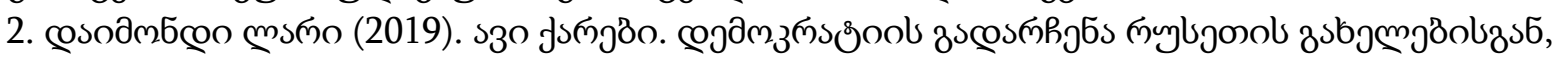

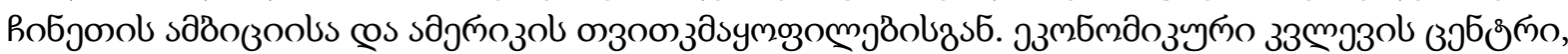
ỏomoluo. 17783 .

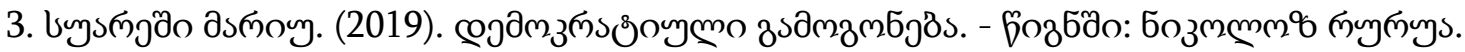

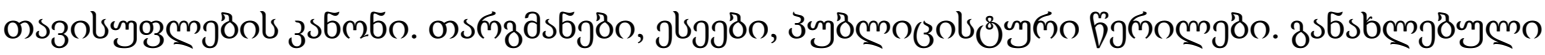

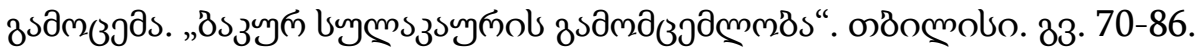

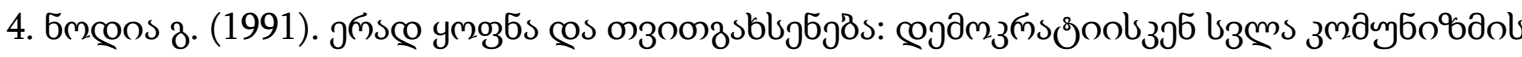

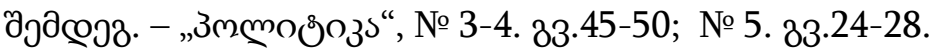

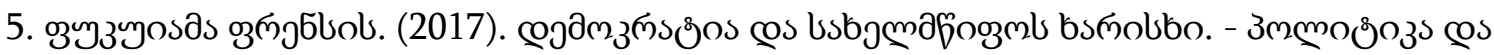

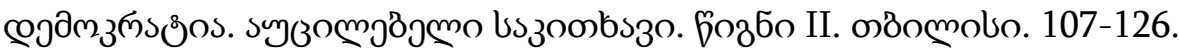

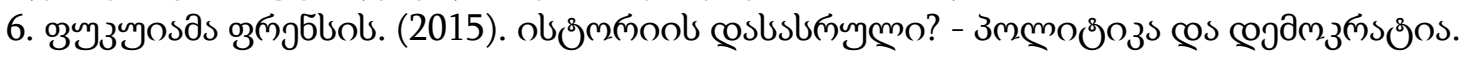

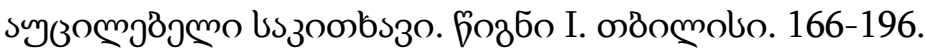

7. Linc Juan. (1978). The Breakdown of Democratic Regimes Crisis, Breakdown and Reequilibration (Baltimore: Johns

Hopkins University Press.

8. Kenneth J. Arrow, (1951). Social Choice and Individual Values (New York: John Wiley.

9. Mancur Olson. (1965).The logic of Logik of Collective Action: Public Goals and the Theory of Groups (Cambridge:

Harvard University Press.

10. Roberto Michels, (1962). Political Parties. A Sociological Study of theOligarchic Tendencies of Moderns Europe

(New York and London: The free Press. 
11. Terri Karl. (1990). "Dilemmas of Democratization in Latin America”. Comparative Politics 23 (Oktober 1990), $1-23$.

12. Даль Р. (2000). О демократии / Пер. с англ. Богдановского А.С. Науч. Ред. Алякринский О.А. М.: Аспект

Пресс. 204 с.

13. Шмиттер Ф.К. (1994). Угрозы и дилеммы демократии.- «Век и Мир», № 7-8, с. 142163.

\title{
„Underwater Reefs” of Democracy
}

Karel Teimuraz

Ilia State University Institute of Political Science

\begin{abstract}
The aim of the article is to discuss the problems of transition from autocraty to democracy. The author analyzing so called "underwater reefs" of democracy marks our internal and extremal dilemmas: oligarchy, self-elimination, "cycling" in politics, functional autonomy, interdependence. The article especially underlines and describes those terma which define the weakness of democracy in the process of transformation: Avolding difficult decisions by politicians due to pressure from interest groups or fear of losing the election Exercising the freedom gained by democracy by interest groups, lobbyists who seek to raise more funds through tax or budget subsidies manipulating very impotant problems for the country as a tool of political struggle failure to keep promises, especially during elections dividing democracy into common and local spheres competent, application structure of the state administration. It also confirms the idea that to elaborate and to carry out of effective political course is available only on the basis of serious empirical research of those problems discussed in the article and the results of these researches.
\end{abstract}

Key words: Democracy; The dilemma of democracy; Autocracy; Underwater reefs; Transformation; Weaknesse of democracy. 